\title{
The Effects of the Internal Flow Structure on SPM Entrapment in the Rotterdam Waterway
}

\author{
MiCHEL A. J. DE NIJS \\ Environmental Fluid Mechanics Section, Delft University of Technology, Delft, Netherlands \\ JOHAN C. WINTERWERP \\ Environmental Fluid Mechanics Section, Delft University of Technology, and Deltares, \\ Delft, Netherlands \\ JULIE D. PIETRZAK \\ Environmental Fluid Mechanics Section, Delft University of Technology, Delft, Netherlands
}

(Manuscript received 3 February 2009, in final form 27 March 2010)

\begin{abstract}
Field measurements are presented, which are the first to quantify the processes influencing the entrapment of suspended particulate matter (SPM) at the limit of saltwater intrusion in the Rotterdam Waterway. The estuarine turbidity maximum (ETM) is shown to be maintained by the trapping of fluvial SPM at the head of the salt wedge. The trapping process is associated with the raining out of fluvial SPM from the upper, fresher part of the water column, into the layer below the pycnocline. The dominant mechanisms responsible are baroclinic shear flows and the abrupt change in turbulent mixing characteristics due to damping of turbulence at the pycnocline. This view contrasts with the assumption of landward transport of marine SPM by asymmetries in bed stress. The SPM transport capacity of the tidal flow is not fully utilized in the ETM, and the ETM is independent of a bed-based supply of mud. This is explained by regular exchange of part of the ETM with harbor basins, which act as efficient sinks, and that the Rotterdam Waterway is not a complete fluvial SPM trap. The supply of SPM by the freshwater discharge ensures that the ETM is maintained over time. Hence, the ETM is an advective phenomenon. Relative motion between SPM and saltwater occurs because of lags introduced by resuspension. Moreover, SPM that lags behind the salt wedge after high water slack (HWS) is eventually recollected at the head. Hence, SPM follows complex transport pathways and the mechanisms involved in trapping and transport of SPM are inherently three-dimensional.
\end{abstract}

\section{Introduction}

Suspended particulate matter (SPM)-laden river waters are conveyed through estuaries toward shelf seas. A typical feature of estuaries is the fresh-saltwater mixing region, an area between fresh and saline waters, which is characterized by high SPM concentrations due to local trapping mechanisms. This along-channel maximum SPM concentration is referred to as the estuarine turbidity maximum (ETM). In some estuarine systems, the ETM is considered an important larval fish nursery area because SPM provides a substrate for organisms, and therefore it

Corresponding author address: Michel A. J. de Nijs, P.O. Box 5048, Stevinweg 1, 2600 GA, Delft, Netherlands.

E-mail: m.a.j.denijs@tudelft.nl plays an essential role in the ecosystem (e.g., North and Houde 2003). However, contaminants also adhere to SPM. Therefore, high contaminant levels can be found in the bed at depositional areas even if the water quality is good. ETMs may also play an important role in the siltation of harbors located on estuarine systems with typically low river turbidity (De Nijs et al. 2008, 2009).

SPM transport pathways, particularly those of fluvial SPM, are of great interest for ecologists; estuarine, river basin, and port management. In consequence, the transport and entrapment processes in the fresh-saltwater mixing region have been the subject of many studies for almost a century. The ETM is a well-documented feature and its widespread occurrence has been confirmed by studies in many estuaries: Chesapeake Bay (Schubel 1968), Columbia River (Gelfenbaum 1983; Jay and Musiak 
1994), Demerara River (Postma 1967), Ems River (Postma 1967), Elbe River (Grabemann et al. 1995, 1996; Kappenberg and Grabemann 2001), Fly River (Wolanski et al. 1995), Gironde Estuary (Allen et al. 1980), Hudson River (Geyer et al. 1998, 2001; Orton and Kineke 2001), Humber-Ouse-Trent (Uncles et al. 2006), Kennebec Bay (Kistner and Pettigrew 2001), Mekong River (Wolanski et al. 1996), Seine River (Avoine et al. 1981; Brennon and Le Hir 1998), Tamar Estuary (Uncles et al. 1985, 1994; Uncles and Stephens 1989, 1993a,b), Tay River (Weir and McManus 1987), Weser River (Wellershaus 1981; Grabemann et al. 1997), Winyah Bay (Patchineelam and Kjerfve 2004), and York River (Lin and Kuo 2001).

Many of the above studies show that the location of ETMs coincides with the limit of saltwater intrusion. In these SPM-trapping regions, storage of mud in the bed and/or heightened SPM concentrations are observed in the water column. Many studies have therefore attributed the presence and distribution of increased SPM concentrations on a tidal time scale to the spatial distribution of erodible SPM in the estuary, such as a "mud reach." In fact, many studies have documented either permanent or temporary storage of mud (during neap tide) in the bed. In that case, an abundant amount of mud is available for transport. Furthermore, during certain tidal periods the entrainment-erosion capacity is too low to deplete the bed of mud. Examples of such cases are the Columbia River (Gelfenbaum 1983), Elbe River (Grabemann et al. 1995; Kappenberg and Grabemann 2001), Fly River (Wolanski et al. 1995), Gironde River (Allen et al. 1980), Hudson River (Geyer 1993; Geyer et al. 1998; Orton and Kineke 2001), Humber-Ouse-Trent (Uncles et al. 2006), Mekong River (Wolanski 1996), Weser River (Wellershaus 1981; Schrottke et al. 2006), Seine River (Brennon and Le Hir 1998, 1999; Le Hir et al. 2001), Tamar River (Uncles and Stephens 1989, 1993a,b; Grabemann et al. 1997), and York River (Lin and Kuo 2001).

Trapped SPM can undergo a continuous cycle of advection, settling, entrainment, and/or erosion for a long period of time (e.g., Schubel 1968; Uncles and Stephens 1993a,b; Wolanski et al. 1996; Grabemann et al. 1997) before permanent deposition occurs in energetically weak regions, such as harbor basins, inlet tributaries, channel network systems, or dead water zones. The manifestation of the aforementioned processes is a cloud of SPM advected up- and down-estuary by the tidal flow on a tidal time scale. In some estuaries, this SPM cloud can have a length scale of several tens of kilometers (e.g., Uncles et al. 2006).

Various theoretical studies have shown that correlations between tidal-averaged, tidal varying, and either depthaveraged quantities and/or vertically varying distributions of velocity and SPM concentration can produce residual landward transports that can balance the seaward transport of SPM by the freshwater discharge. These processes include gravitational circulation (Postma 1967; Festa and Hansen 1978), internal tidal asymmetry (Jay and Musiak 1994, 1996), front formation (Geyer et al. 1998), formation of exchange flows in combination with turbulence damping (Geyer 1993), settling lag (Postma 1961; Groen 1967), scour lag (Postma 1961), and barotropic tidal asymmetry (Allen et al. 1980; Speer and Aubrey 1985; Dronkers 1986). These studies indicate that the along-channel distribution of salinity and SPM are related features in estuarine environments. They also show that the salinityinduced density structure provides sufficient conditions to maintain an ETM near the limit of saltwater intrusion, independent of a bed supply of mud. The dynamics of the ETM are not necessarily determined by the behavior of cohesive sediment, such as flocculation, consolidation, and sediment-induced density effects. Furthermore 3D numerical simulations by Burchard and Baumert (1998) and Brennon and Le Hir (1999) support this.

Burchard and Baumert (1998) conducted numerical experiments to determine the relative contribution of the gravitational flow and the time-dependent internal velocity and mixing asymmetry to the formation of an ETM near the tip of a salt wedge. They concluded that only the first two mechanisms are necessary to create an ETM. Furthermore, they deduced that the role of tidal velocity asymmetry in the ETM formation process is more important than that of the (residual) gravitational flow.

Based on the results of numerical simulations, Geyer (1993) demonstrated that stratification led to the suppression of turbulence at the pycnocline and an associated reduction in the quantity of SPM that can be carried by the flow. In consequence, the trapping of SPM at the landward limit of the salinity intrusion is greatly enhanced. Furthermore, Geyer et al. (2000) found that bed-generated turbulence was confined beneath the pycnocline and therefore the estuarine circulation in the Hudson River was controlled by the bed stress. However, the consequences of these processes on time-dependent SPM entrapment have not been discussed.

This paper is part of a series, in which we have addressed the relationship between the ETM and harbor siltation (De Nijs et al. 2008, 2009) and the physics controlling the internal flow structure (De Nijs et al. 2010). Many authors have focused on either internal or on barotropic tidal asymmetry to deduce a landward transport of SPM. However, in De Nijs et al. (2010) it was demonstrated that barotropic tidal asymmetry, imposed at the mouth of the Rotterdam Waterway, controlled the advection of the salt wedge and therefore the subsequent evolution of the internal flow structure. In agreement 
with the mechanism proposed by Geyer (1993), it was shown that stratification led to decoupling effects between the layers because of suppression of turbulence at the pycnocline, and that bed-generated turbulence was confined beneath it. In consequence, De Nijs et al. (2010) found the time-dependent behavior of the internal flow structure to be governed by the tidal displacement of the salt wedge, which controlled the height of the pycnocline above the bed at a particular site and therefore the height to which bed-generated turbulence can protrude into the water column. Here, we investigate the implications of this time-dependent physical mechanism on ETM formation and SPM distribution. To our knowledge this is the first study to do so.

Here we describe the results of a study designed to investigate time-dependent SPM entrapment and the behavior of the ETM in the Rotterdam Waterway, Netherlands. It is also the first study to verify the existence of an ETM in the Rotterdam Waterway (De Nijs et al. 2008, 2009). To establish the nature of the underlying time-dependent processes and the interactions contributing to the entrapment of SPM on a tidal time scale, high frequency measurements at several positions along the estuary are required. Therefore, a detailed field survey was carried out in the Rotterdam Waterway, which is described in section 2. In section 3 it is shown that the salt wedge, with its associated near-bed convergence, as well as an abrupt change in turbulent mixing characteristics plays an important role in keeping predominantly fluvial SPM in the Rotterdam Waterway. If one looks again at the mechanism proposed by Geyer (1993), it is immediately obvious that any fluvial source of SPM will be inefficiently transported to the outer estuary as a result of a reduction in SPM carrying capacity of the flow above a pycnocline. Therefore, we also make use of data on the origin of the SPM in the Rotterdam Waterway in section 3. We do this in order to investigate the role played by the time-dependent mechanism of De Nijs et al. (2010) on the distribution of SPM within the estuary. We show that the salt wedge behaves like a sediment sieve, sorting the sediment along the estuary. We discuss the implications of this time-dependent mechanism in section 4 .

\section{Methods}

\section{a. Field site}

The lower river branches of the Rhine and Meuse rivers form an estuary called the Rhine-Meuse estuary (Fig. 1). The cross sections in the downstream parts of the estuary are approximately prismatic. Farther upestuary, a distinction can be made between main channel and floodplain, here only a part of the cross section contributes to storage of water. Down-estuary and in the middle part of the estuary, harbors, and cutoff river branches contribute to storage of water. The bed material in the Rotterdam Waterway generally consists of fine and medium sand as the system is too dynamic to favor siltation of mud on the riverbed. Most of the dredging in the Rotterdam Waterway occurs in the river bend at Maassluis. The dredged material is mainly sand; hardly any mud is dredged. However, in the harbor basins of the Port of Rotterdam, mud is the dominant constituent of the dredged material.

\section{b. Survey setup and hydrodynamic conditions}

The 13-h boat survey was carried out on 11 April 2006 prior to spring (full moon was 13 April) at times of higher discharges. Rhine discharges varied from $5800 \mathrm{~m}^{3} \mathrm{~s}^{-1}$ at the beginning of April to about $4000 \mathrm{~m}^{3} \mathrm{~s}^{-1}$ at the day of the survey. Mean water level changes preceding and during this survey were smaller than about $0.30 \mathrm{~m}$. This survey included eight measuring stations (Fig. 1). The stations were set up to characterize the (internal) tidal velocity, salinity, and SPM concentration field along the longitudinal axis of the Rotterdam Waterway at sites where saltwater is permanently present, during a part of the tidal cycle and outside the influence sphere of the salt wedge. Three stations (stations 1,6, and 7) measured at the boundaries of a balance area (see section 3c) to quantify the gross physical mechanisms contributing to mass transport and to determine the ETM formation time scale. One vessel (station 8) measured the evolution of velocity and salinity in a frame of reference moving with the salt wedge. This style of measuring corresponds with the Lagrangian description of the ETM dynamics presented in De Nijs et al. (2008).

\section{c. Instruments and procedures}

\section{1) CONVENTIONAL CTD AND TURBIDITY INSTRUMENTS AND PROFILING PROCEDURES}

Optical backscatter (OBS) instruments (OBS-3 and OBS-3A) were used to measure turbidity profiles. The OBS-3A combines an OBS probe with conductivity, temperature, and depth (CTD) sensors. OBS-3 probes were mounted on frames with CT probes and pressure sensors at the same level. A comprehensive summary of the OBS measuring principle can be found in Downing (2006). Water samples have been taken to calibrate the instruments. The OBS-3A operated with a maximal frequency response of $2 \mathrm{~Hz}$, while the OBS- 3 and CT probes had a maximal frequency response of $1 \mathrm{~Hz}$. The instruments operated with an SPM concentration measuring range of approximately $0-8 \mathrm{~kg} \mathrm{~m}^{-3}$. A routine of profiling was employed where the sensors moved 


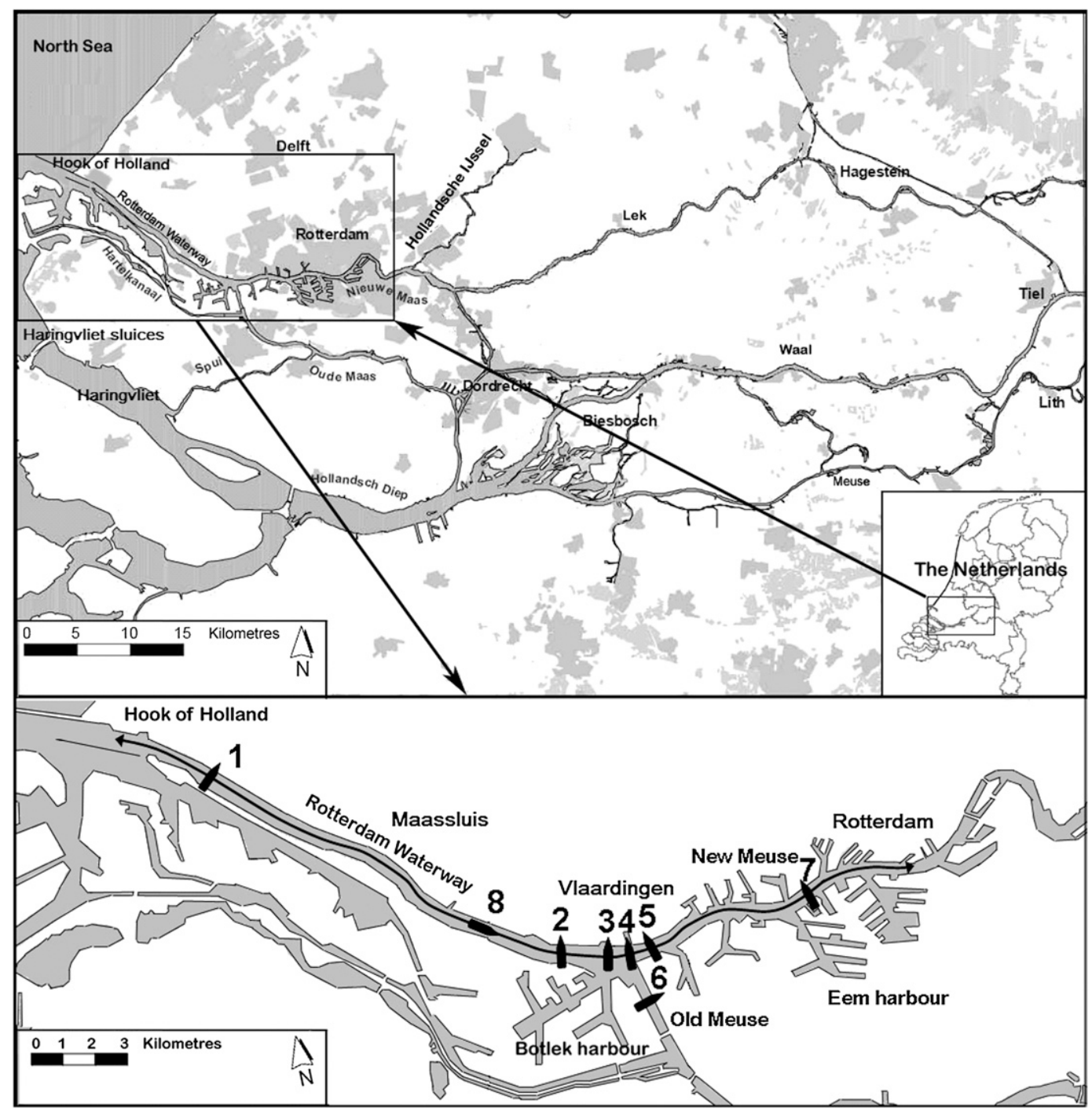

FIG. 1. (top) The Rhine-Meuse estuary and (bottom) the Port of Rotterdam including the Rotterdam Waterway, New Meuse, and Old Meuse. The up-estuary borders (i.e., no tide), outside the domain of Fig. 1, are approximately at the cities Hagestein, Tiel, and Lith located along the rivers Lek, Waal, and Meuse, respectively. The down-estuary borders are at Hook of Holland and at the Haringvliet sluices, which form open and regulated connections to the North Sea. The Port of Rotterdam and Botlek Harbor are part of this estuarine system. An overview of the setup of the boat survey on 11 Apr 2006 with the location of the seven stations is given in the map of the Port of Rotterdam. The stations were set up to characterize the tidal velocity and salinity field along the longitudinal axis of the Rotterdam Waterway. The seven stations include sites where saltwater is permanently present, station 1, stations 2-6 where saltwater is present during only a part of the tidal cycle, and station 7 , which is always in the freshwater region. This setup was designed to distinguish between advection and local processes, and to examine the processes that control the structure of the salt wedge during tidal excursions.

through the water column while data was continuously logged. Hence, instantaneous flow properties were measured. Different speeds of the instrument frames winches, ranging from 0.05 to $1 \mathrm{~m} \mathrm{~s}^{-1}$, have been used over the water column (De Nijs et al. 2009, 2010) to better profile the near-bed region where large salinity and SPM gradients occur. The recording ended when the bed was reached (criterion: pressure did not increase). The time to complete a downcast amounted to about 90 to $100 \mathrm{~s}$. Weights were attached to the instrument frames to prevent large deviations from the vertical because of current drag. Only at locations 3, 4, and 5 (Fig. 1), was it possible to attach these weights above the instruments. Therefore, at other locations the near-bed region and bed may not have been completely profiled and/or properly detected. 


\section{2) Siltprofiler}

Characteristic for estuarine environments is that SPM concentrations can range from low surface SPM concentrations of approximately $0.01-0.05 \mathrm{~kg} \mathrm{~m}^{-3}$ to fluid mud concentrations near the bed larger than $10 \mathrm{~kg} \mathrm{~m}^{-3}$. This SPM concentration range is difficult to reliably measure with conventional instrument packages such as the OBS-3A. Furthermore, conventional CTD-turbidity sensor packages lack the capability to provide high vertical resolution needed to measure phenomena such as pycnoclines, lutoclines, and relative thin fluid mud layers. The routine of profiling also takes a relatively long time due to low winch speeds during downcasts.

A high resolution Siltprofiler has been developed to improve on the aforementioned routine of profiling. Dr. Robbert Kirby from Ravensrodd Consultants, Ltd., has provided the blueprints for this device. The Siltprofiler concept has been further developed at Delft Hydraulics in collaboration with Dr. Kirby. This profiler is equipped with sensors that measure with high frequency (80$100 \mathrm{~Hz}$ ). These sensors comprise CTD and three turbidity sensors. The latter sensors cover three distinct measuring ranges. A Seapoint optical backscatter sensor covers the first measuring range $\left(0-1 \mathrm{~kg} \mathrm{~m}^{-3}\right)$, the second (1-10 $\left.\mathrm{kg} \mathrm{m}^{-3}\right)$, and third ranges are covered by infrared extinction sensors $\left(10-35 \mathrm{~kg} \mathrm{~m}^{-3}\right)$. The Siltprofiler is deployed freefalling. The falling speed amounts approximately to $1 \mathrm{~m} \mathrm{~s}^{-1}$. A Bluetooth connection (wireless) transmits the data when it surfaces.

\section{3) BOAT-MOUNTED ADCP VELOCITY MEASUREMENTS}

Velocity measurements were collected with boatmounted acoustic Doppler current profilers (ADCPs). The ADCPs deployed during the boat surveys were RD instruments acoustic Doppler current profilers 1200-kHztype broadband. The depth range covered by the ADCPs is $20 \mathrm{~m}$. These transects were navigated approximately perpendicular to the channel and basin axis. The procedures and settings have been described in De Nijs et al. (2009, 2010).

\section{4) WATER SPAMPLING, GRAVIMETRIC ANALYSIS, AND CALIBRATION}

The phenomena of interest occur within a relatively short time period. Therefore a routine of turbidity profiling had to be applied, which ensures high temporal resolution profiling. It was therefore decided to pump water samples, instead of sampling with bottles. The nozzle of the pump sampler was mounted on a frame along with other measuring equipment. The intake aligns itself against the primary flow. The intake velocity was approximately $0.12 \mathrm{~m} \mathrm{~s}^{-1}$.

Water sampling was carried out at positions 1,2 , and 5 at phases of the tide when the flow velocity was either low (slack) or high (flood and ebb). During this 13-h survey approximately five sampling periods occurred. Samples were taken at approximately 0.5 and $3 \mathrm{~m}$ from the bed, and $3 \mathrm{~m}$ below the free surface. One-liter water samples were taken, which were stored in darkness at $4^{\circ} \mathrm{C}$ in order to avoid primary production before conducting gravimetric analysis according to the Dutch norm NEN 6484.

The OBS sensors were first calibrated for turbidity (FTU) using formazin mixtures. They then were calibrated for SPM $\left(\mathrm{kg} \mathrm{m}^{-3}\right)$ by combining water sample data from different locations. In this analysis water samples obtained near the bed and with a dry-weight below $0.01 \mathrm{~kg} \mathrm{~m}^{-3}$ have been left out because of positioning problems and accuracy constraints imposed by the gravimetric analysis. As a result, the number of calibration points became too small to determine calibration curves per location. The turbidity sensors mounted on the Siltprofiler have been calibrated using bed samples obtained at the turning circle of Botlek Harbor.

\section{d. Data processing}

Principal component analysis (Emery and Thomson 2001) has been used to determine the principal axes and velocities along the direction of maximum and minimum variance. The first velocities are referred to as primary or along-channel velocity components, and the latter as secondary or traverse velocity components. The velocity data near the surface (blanking distance) and near the bed (side lobe effects) have been reconstructed by block extrapolation and a power law description (van Veen 1938) based on the velocity found in the near surface and deepest profiling point, respectively. Time versus depth information has been obtained by collecting ADCP transect data nearest to the CTD-turbidity profiling points. To be able to determine fluxes the data were gridded onto a regular grid with approximately the same density as the profiling data using linear Delaunay triangulation (interpolation). A 2D spatial filter (3 by 3 block weighted) has been used to smooth the results. Measurements collected with the Siltprofiler were smoothened using polynomial fits of order 6 .

\section{e. Estimation of profiles of Reynolds stresses, turbulent viscosities, and SPM carrying capacity of the flow}

Reynolds stress terms are estimated from a simplified along-channel momentum balance 


$$
\int_{z=z^{*}}^{\eta} \frac{\partial}{\partial z}\langle u w\rangle d z=-\int_{z=z^{*}}^{\eta}\left(\frac{\partial u}{\partial t}+u \frac{\partial u}{\partial x}+g \frac{\partial \eta}{\partial x}+\int_{z=z^{*}}^{\eta} \frac{g}{\rho_{0}} \frac{\partial \rho}{\partial x} d z+\frac{\partial\langle u u\rangle}{\partial x}\right) d z+\tau_{s},
$$

with $u$ the along-channel or primary velocity component, $\eta$ the water level, $\rho$ the density of the water, $\rho_{0}$ the reference density of water, $\langle u u\rangle$ a normal Reynolds stress, $\langle u w\rangle$ a Reynolds shear stress, and $\tau_{s}$ the surface stress. The up-estuary direction is taken positive. Note that these calculations are estimates only since proper ensemble averaging could not be applied. The $\langle u w\rangle$ estimates are calculated from the data at stations 1 and 2, based on the vertical integral of terms 1,3 , and 4 on the right-hand side of Eq. (1). The stress at the surface is assumed to be zero. Term 3 has been calculated from fixed water level stations (see De Nijs et al. 2010). Term 4 has been estimated from the along-channel scalar conservation equation neglecting turbulent diffusion, and transverse and vertical terms (e.g., Geyer et al. 2000) for $|u|$ $>0.25 \mathrm{~m} \mathrm{~s}^{-1}$. These estimates have been made consistent with baroclinic pressure gradients estimated from data collected from successive passages through the head of the salt wedge. The distribution of the turbulent viscosity has been calculated assuming gradient type transport.

\section{f. Decomposition of the total mass transport}

Fischer (1972) presented a method for the decomposition of the total mass transport in an estuary. Dyer (1974) and Winterwerp (1983) performed similar analyses where they both assume that lateral transport effects are negligible and that the along-channel velocity profile is representative for the cross-sectional mean value. Here we follow the method in Winterwerp (1983) and highlight the individual mechanisms contributing to the mass transport of salt and SPM; see also De Nijs et al. (2009) for a detailed description. The instantaneous and tidal and cross-sectional-averaged salinity or SPM transport per unit width are given by

$$
\begin{aligned}
\int_{0}^{h} u c d z d t= & h\left(\bar{u}_{0} \bar{c}_{0}+\bar{u}_{0} \bar{c}_{t}+\bar{u}_{t} \bar{c}_{0}+\bar{u}_{t} \bar{c}_{t}\right. \\
& \left.+\overline{u_{0}^{\prime} c_{0}^{\prime}}+\overline{u_{0}^{\prime} c_{t}^{\prime}}+\overline{u_{t}^{\prime} c_{0}^{\prime}}+\overline{u_{t}^{\prime} c_{t}^{\prime}}\right)
\end{aligned}
$$

and

$$
\begin{aligned}
\frac{1}{T} \int_{0}^{T} \int_{0}^{h} u c d z d t= & h_{0} \bar{u}_{0} \bar{c}_{0}+\bar{u}_{0}\left\langle h \bar{c}_{t}\right\rangle+\left\langle h_{t} \bar{u}_{t}\right\rangle \bar{c}_{0} \\
& \left.+\left\langle h \bar{u}_{t} \bar{c}_{t}\right\rangle+h_{0} \overline{u_{0}^{\prime} c_{0}^{\prime}}\right\rangle+\left\langle h \overline{u_{0}^{\prime} c_{t}^{\prime}}\right\rangle \\
& +\left\langle h \overline{u_{t}^{\prime} c_{0}^{\prime}}\right\rangle+\left\langle h \overline{u_{t}^{\prime} c_{t}^{\prime}}\right\rangle
\end{aligned}
$$

where the $\langle\cdot\rangle$ symbol denotes a tidally averaged quantity. The eight terms can be attributed to 1) freshwater discharge, 2) tidal pumping (Dyer 1997), 3) Stokes drift, 4) transport by trapping (Fischer et al. 1979) that Dyer (1997) refers to as tidal pumping. The term tidal pumping is associated in the literature with landward transport driven by tidal phase differences and tidal asymmetry in combination with sediment-induced lag effects as a result of settling and resuspension. Term 5 is associated with the gravitational circulation. Terms $6-8$ indicate changing profiles within the tide that can be attributed to baroclinic shear flows and internal tidal asymmetry. The eight terms on the right-hand sides of Eqs. (2) and (3) will be referred to as T1-T8 and TT1-TT8, respectively, below.

\section{Results}

\section{a. An Eulerian perspective on the dynamics of the ETM}

\section{1) FiXed STAtions}

The evolution of the vertical profiles of salinity, SPM concentration, and velocity, recorded at the fixed stations, are presented in Figs. 2 and 3. Figure 4 shows time series of water level, salinity, SPM, velocity, direction, and SPM transport near the surface and near the bed at fixed stations. In general, the background concentrations of SPM are low; with the surface SPM concentrations varying between $\sim 0.02$ and $0.05 \mathrm{~kg} \mathrm{~m}^{-3}$. High values of SPM near the bed of $\sim 0.8 \mathrm{~kg} \mathrm{~m}^{-3}$ are advected with the salt wedge. However, settling of SPM around LW and HW slack only leads to the development of relatively low near-bed SPM concentration layers of $\sim 0.1 \mathrm{~kg} \mathrm{~m}^{-3}$.

The observed increase in the concentration of SPM after slack tide, stations 2, 3 (not shown; see De Nijs 2010), 5 and 6 is caused initially by reentrainment of SPM from the bed, followed by advection of SPM with the head of the salt wedge. Stations 2 to 6 were located within a tidal excursion from each other. The measurements at stations 2, 3 (not shown), 5, and 6 show the advection of clouds of SPM out of the Old and New Meuse during ebb (station 2: 0600-0700 and 0730-1000; station 5: 0700-1000; station 6: 0600-0630) and bifurcation of the ETM at the junction of the Old and New Meuse during flood at $\sim 1600$ (stations 2,5 , and 6). The time lag between maximum SPM concentration (Figs. 2 and 4) and maximum near-bed velocity (Figs. 3 and 4), in combination with the correlated increase of salinity and turbidity, suggests that high SPM concentrations are the result of advection of the ETM toward the measuring 

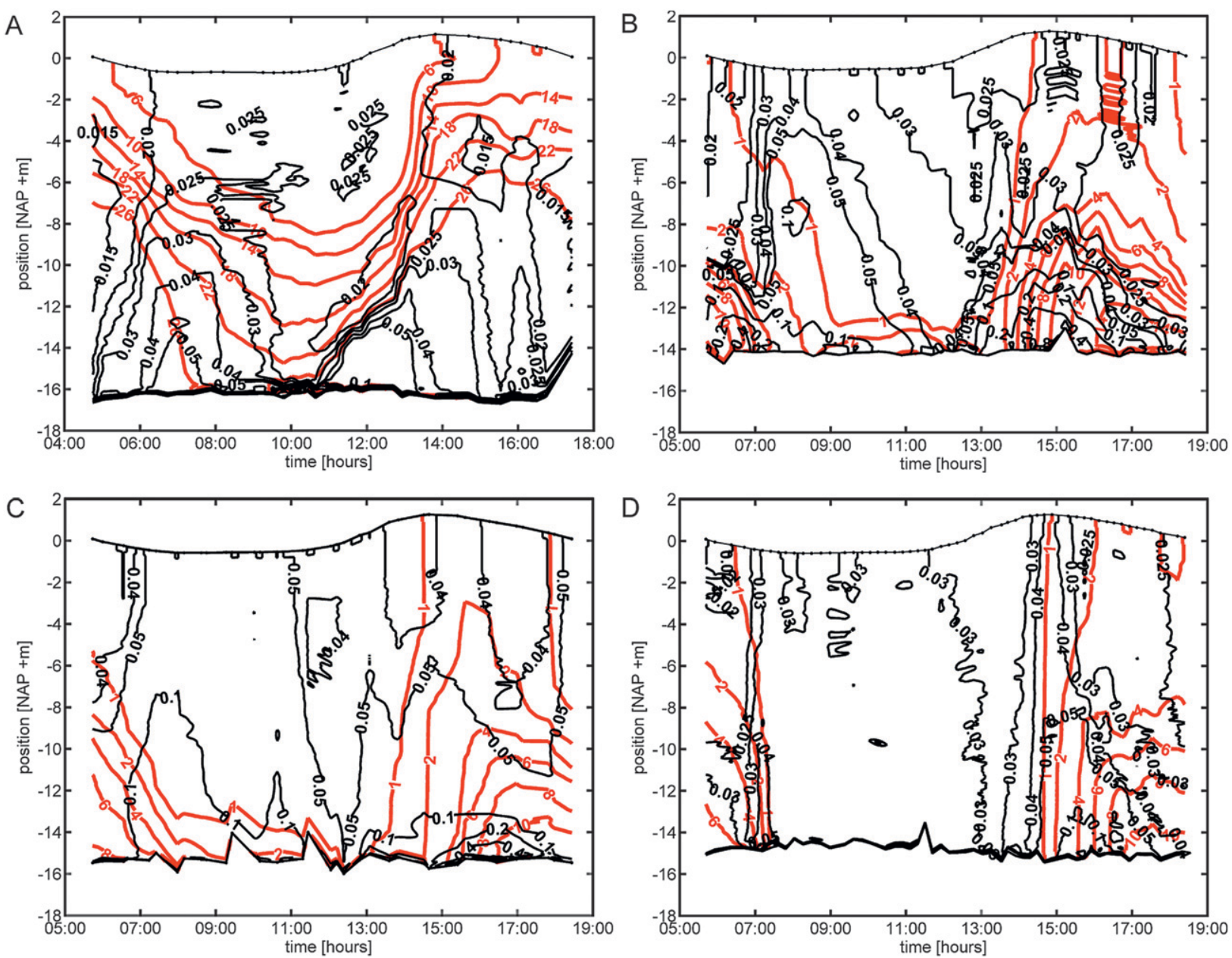

FIG. 2. Time series of vertical profiles of salinity (PSU) indicated by the blue lines and SPM concentration $\left(\mathrm{kg} \mathrm{m}^{-3}\right)$ indicated by the black lines recorded at stations (a) 1, (b) 2, (c) 5, and (d) 6 during the survey on 11 Apr 2006 [section 4c(4), Fig. 4]. The time of the survey is shown on the abscissa and position within the water column on the ordinate. The reference frame used in Netherlands is the Normaal Amsterdamse Peil (NAP). The gray contours depict salinity and the black contours SPM concentration. Saline water was present on both the flood and ebb at station 1, whereas station 7 was located outside the range of the salt wedge. Station 4 is not included, as it is similar to stations 3 and 5. Station 3 had a lower measuring frequency than station 2.

locations. Advection dominates the SPM signal over local entrainment.

In particular, the measurements at stations 2, 3 (not shown), and 5 show a distinct cloud of SPM below the pycnocline during ebb (Fig. 2; 0600-0800). However, stations 2 and 5 also show a less distinct patch of SPM $(\sim 0730-1000)$ in the fresher waters, which lags behind the salt wedge. This latter patch is due to SPM that has diffused higher into the water column. It is evident that clouds of SPM are advected up-estuary with the salt wedge, as the salt wedge retreats any deposited bed material can then be resuspended as the current increases. Therefore, the lags probably indicate relative movement between the saltwater and SPM in the New Meuse (station 5) due to resuspension (Figs. 3 and 4). The high water slack (HWS) period and therefore the amount of SPM that settles is larger in the New Meuse (station 5) than in the Old Meuse (station 6; Figs. 3 and 4; see also De Nijs et al. 2010). Therefore, the observation of SPM lagging saltwater is more distinct in the New Meuse.

\section{2) THE EFFECTS OF SALINITY STRATIFICATION ON TURBULENT MIXING}

To understand the effects of salinity stratification on the distribution of SPM, the evolution of SPM concentration distribution, pycnocline height and gradient Richardson numbers at the pycnocline at stations 1,2,3, and 6 are presented in Fig. 5. The values of the gradient Richardson numbers are above 0.25 . This suggests that the pycnocline confines turbulence induced mixing to the region near the bed. Turbulence can mix SPM below 

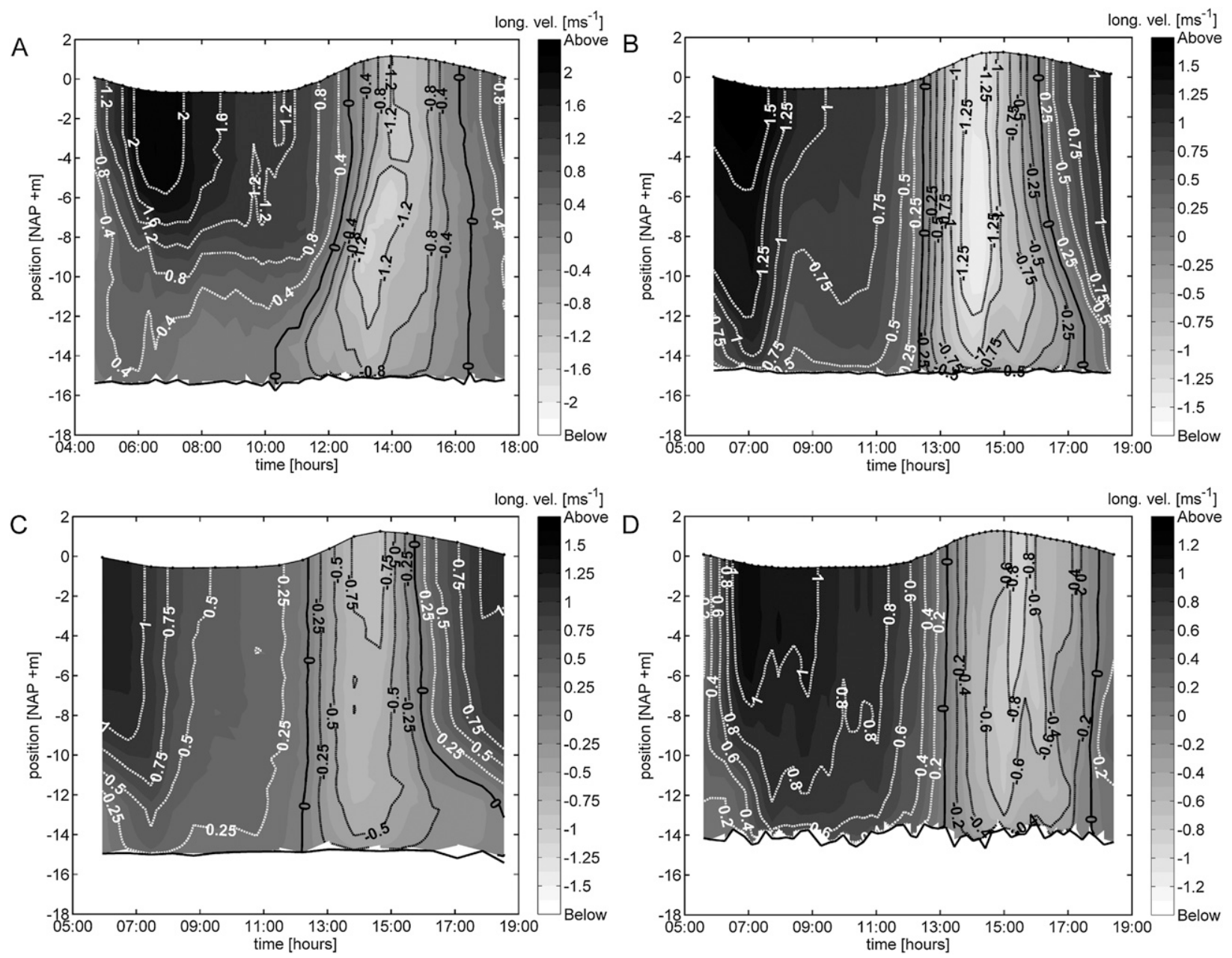

FIG. 3. Time series of vertical profiles of velocity $\left(\mathrm{m} \mathrm{s}^{-1}\right.$ ) recorded at stations (a) 1, (b) 2, (c) 5, and (d) 6 during the survey on 11 Apr 2006. The time of the survey is shown on the abscissa and position within the water column on the ordinate. The reference frame used in the Netherlands for heights is the NAP. The gray colors and contour lines depict velocity, with positive values indicating ebb. Saline water was present on both the flood and ebb at station 1, whereas station 7 was located outside the range of the salt wedge. Station 4 is not included in the figures, as it is similar to stations 3 and 5.

the pycnocline during ebb-flood advection periods, but above the pycnocline, SPM concentrations are low. During ebb, the maximal Reynolds stress value is lower and occurs somewhat higher above the bed than on flood, Fig. 6. This is because the baroclinic pressure gradient reinforces the tidal barotropic pressure gradient on flood and opposes it on ebb. Figure 7 shows turbulent viscosity profiles, with maximal values in the region near the bed (stations 1 and 2) and at middepth (station 1) and a marked decrease with height above the pycnocline. In consequence, Fig. 7 shows how the pycnocline position in the water column controls the distribution of the turbulent viscosity at station 1 . The height of the pycnocline above the bed and the maximal turbulent viscosity values above bed decrease during ebb, and vice versa during flood, due to down-estuary and up-estuary advection of the salt wedge by the tide, respectively (see De Nijs et al. 2010).

\section{3) Along-Channel transects}

A mechanistic description of the SPM trapping processes can be derived from the data collected during the repeated along-channel transects through the head of the salt wedge (Figs. 8a-f). Transects 3, 5, and 10 (Figs. 8f,b,c, respectively), show that the velocity and transport gradients are directed into the salt wedge during ebb, which indicates horizontal trapping. Middepth velocity maxima are evident on the flood, transects 5 and 6 (Figs. $8 \mathrm{c}, \mathrm{d}$, respectively) at the location of the pycnocline. Around slack water exchange flows are set up by the baroclinic pressure gradient. These exchange flows are evident in transects 3 and 5 (Figs. 8b,c, respectively) 

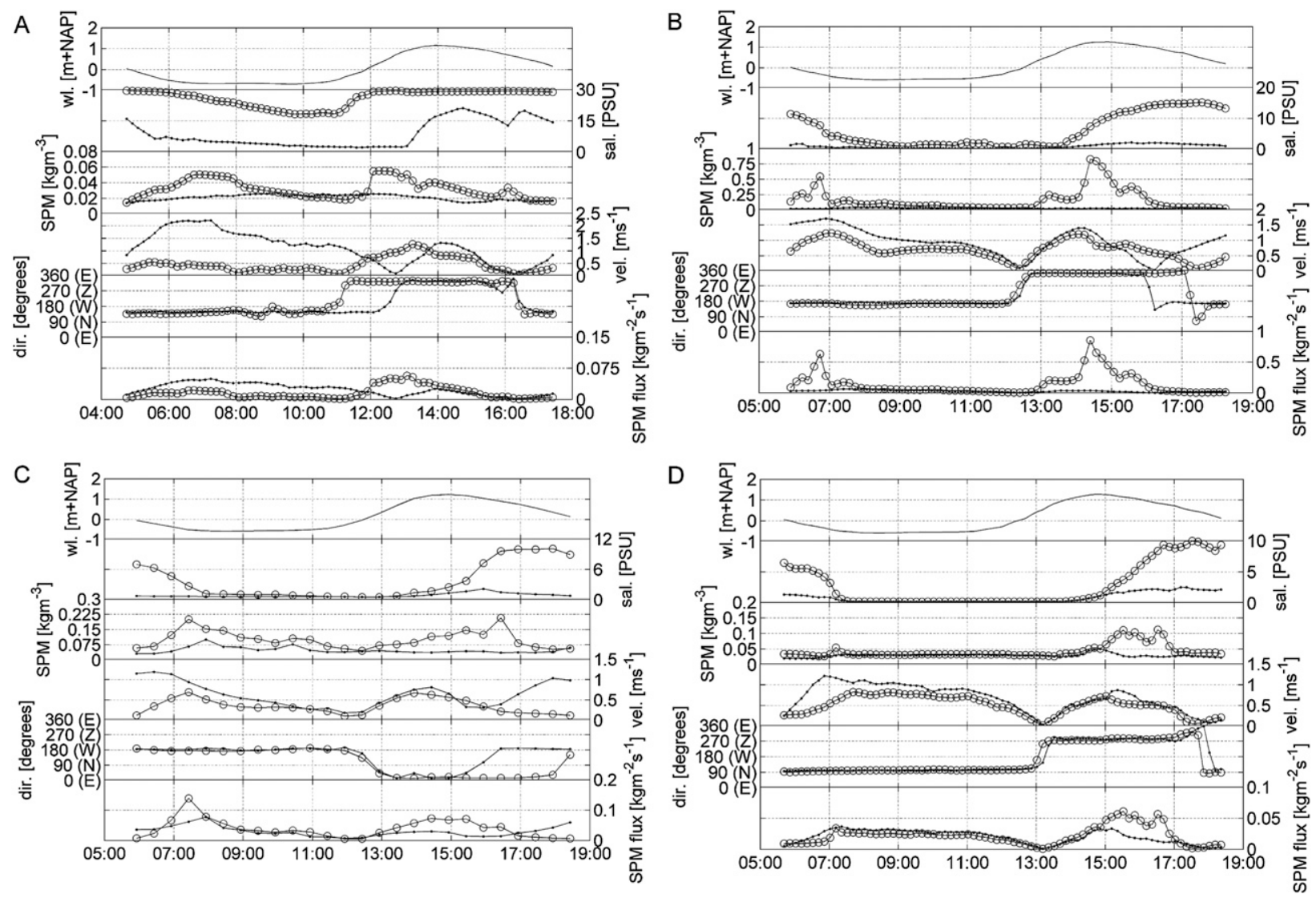

FIG. 4. The recorded water level, salinity, SPM concentration, velocity magnitude, flow direction, and transport of SPM (top to bottom, respectively, in each panel) at stations (a) 1, (b) 2, (c) 5, and (d) 6 . The data are located at fixed heights NAP - 3 m near the surface (dots) and NAP $-13 \mathrm{~m}$ near the bed (open circles).

recorded at low water slack (LWS) and transects 9 and 10 (Figs. 8e,f, respectively) recorded at HWS. Moreover transects 2-3 (Figs. 8a,b, respectively) and 10 (Fig. 8f), highlight a substantial seaward decrease in the nearsurface SPM levels over the length of the salt wedge.

The effects of turbulence damping at the pycnocline, on the raining out of SPM from the layer above the pycnocline are apparent. This is in agreement with the mechanism proposed by Geyer (1993) and the time dependent extension of this mechanism described in De Nijs et al. (2010). This suggests that there is a fluvial source of SPM. Once these SPM-laden upstream waters encounter the salt wedge, stratification leads to a shut down of turbulence, which leads to enhanced trapping of SPM at the limit of saltwater intrusion. Note that transect 2 (Fig. 8a) shows a large surface gradient in SPM concentration with values of $0.03 \mathrm{~kg} \mathrm{~m}^{-3}$ near kilometer 10 and $0.08 \mathrm{~kg} \mathrm{~m}^{-3}$ near kilometer 18 , as does transect 3 (Fig. 8b). Transects 2 and 3 (Figs. 8a,b, respectively) also show a cloud of SPM in front of the salt wedge in the fresher waters $(\sim 0730-0900)$. The transects are recorded at the time of large ebb currents and the SPM upstream of the salt wedge has been resuspended.

A comparison of transects 2-3 (Figs. 8a,b, respectively), with transect 6 (Fig. 8d), shows higher SPM levels above the pycnocline during ebb than flood. Furthermore, from a comparison of transects 2 and 3 (Figs. 8a,b, respectively) with 9 (Fig. 8e), it can be deduced that at HWS, water with lower SPM levels is first advected over the head of the salt wedge, and is then subsequently followed by water with higher SPM levels from up-estuary. This is due to the effects of differential advection at late flood and the effects of turbulence damping.

\section{b. A picture of the dynamics of the ETM in a frame of reference moving with the salt wedge}

Here the data collected from the repeated alongchannel transects through the head of the salt wedge are used to present a picture of the evolution of the alongchannel distribution of salinity, SPM concentration and velocity in a frame of reference moving with the salt wedge (Figs. 9-11). The most striking result from this method of presentation is that one easily identifies the 

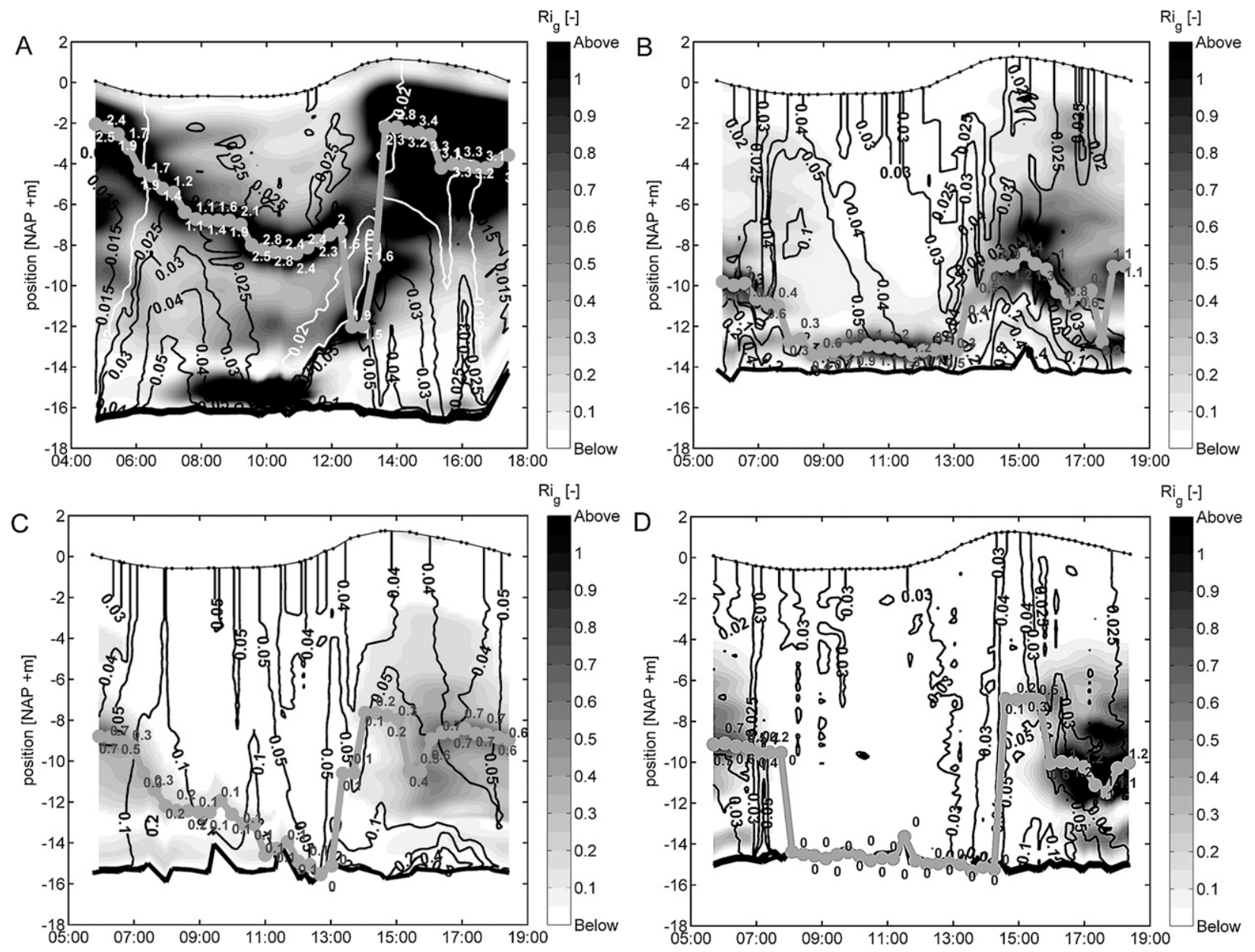

FIG. 5. Time series of vertical profiles of SPM concentration and gradient Richardson number $\left(\mathrm{Ri}_{g}\right)$ recorded at stations (a) 1, (b) 2, (c) 5, and (d) 6 during the survey on 11 Apr 2006. The time of the survey is shown on the $x$ axis and position within the water column on the $y$ axis. The black and white contours depict SPM concentration, the gray colors depict gradient Richardson numbers and the gray line, the position in the water column of maximum gradient Richardson number. The labels indicate the value of the maximum gradient Richardson number.

phase difference between the times of maximum SPM concentration in the waters above and below the pycnocline, the decrease in the near surface values of SPM in the seaward direction, and the higher near surface SPM concentrations on the ebb than on the flood. Moreover the path taken by a particle of sediment during the tidal cycle can be deduced.

The advection of the salt wedge and ETM into the Botlek Harbor region during flood tide is evident (Figs. 9 and 10 lower panels; 1200-1600). It is known from data collected at a mooring within Botlek Harbor that part of the SPM in the ETM exchanged with Botlek Harbor around high water (HW) 1500 (De Nijs et al. $2008 a, b)$. Salt and turbid water bifurcated into the Old Meuse and New Meuse (Figs. 9 and 10; 1600). At the limit of saltwater intrusion, ebb tide started first near the bed in the Old Meuse followed by the Rotterdam
Waterway and New Meuse, (Fig. 3; stations 5 and 6; see also De Nijs et al. 2010). Subsequently, the patches of SPM and saltwater were advected out of both channels into the Rotterdam Waterway during ebb, but at different phases of the tide. This is noticeable in Fig. 10 (lower panel; 0800-1000) by the presence of the two clouds of SPM; cloud 1 at the $0.3 \mathrm{~kg} \mathrm{~m}^{-3}$ and cloud 2 at the $0.2 \mathrm{~kg} \mathrm{~m}^{-3}$ contour line, respectively. The SPM in the different clouds deposits at $\sim 0900-1100$ in approximately the same area of the river, down-estuary of Botlek Harbor at LWS. Because of flood resuspension a single cloud starts to form again at $\sim 1100-1200, \sim 6 \mathrm{~km}$ inland.

The corresponding velocity field (Fig. 11) indicates that around slack water lower SPM concentrations (Fig. 10) occurred than during the previous ebb and flood period. Figs. 9 and 11 also show that exchange flows are 

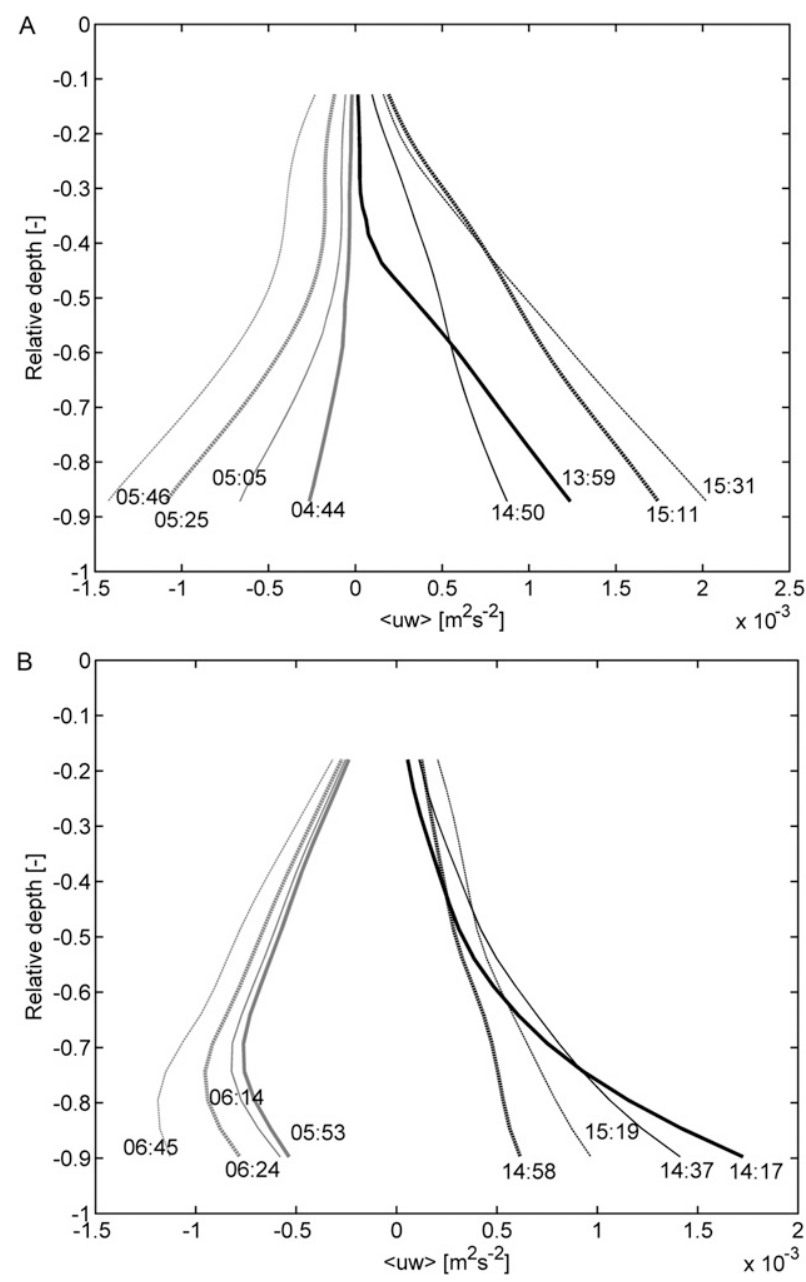

FIG. 6. Vertical profiles of the Reynolds shear stress $(\langle u w\rangle)$ at selected times during ebb and flood at stations (a) 1 and (b) 2.

set up around LWS (0900-1200) and HWS (1600-1800). The SPM trapping processes associated with the exchange flows are differential advection and near-bed flow convergence. Subsequently, fluvial SPM advected over saltier water settles from the upper freshwater into the lower saltwater layer due to the effects of buoyancy forces on the damping of turbulence at the pycnocline (Fig. 10). At the head of the salt wedge near-bed flows and transports converge, because of the effects of the baroclinic pressure gradient on the current field (Figs. 8 and 11). These processes, combined with velocity and transport gradients over the length of the salt wedge during ebb (Fig. 8), set up by the baroclinic pressure gradient, and a relatively large near-bed LWS period at the head of the salt wedge (Figs. 8 and 11), explain the accumulation of SPM at approximately the same area around LWS (see Fig. 10 lower panel; 0900-1200). The LWS period is longer than the HWS period because the barotropic pressure gradient remains small and constant
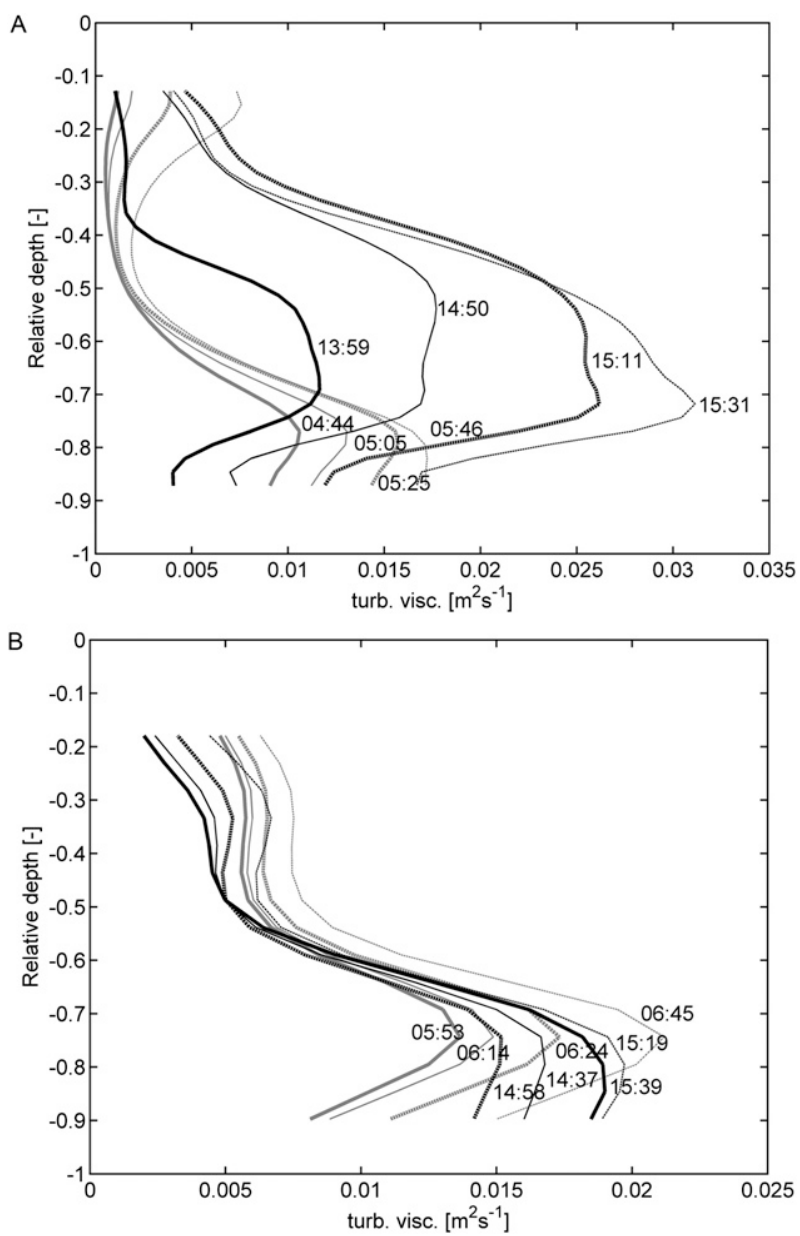

FIG. 7. Turbulent viscosity profiles at selected times during ebb and flood at stations (a) 1 and (b) 2 estimated from the Reynolds shear stress $(\langle u w\rangle)$ and shear.

through the period low water (LW) to LWS. This is due to the nature of the tidal water level asymmetry (the double LW); see De Nijs et al. (2010).

\section{SEDIMENT PARTICLE TRANSPORT PATHWAYS}

At late flood, near-surface water with low SPM concentrations overtakes the head of the salt wedge, Figs. 8, 9,10 , and 11. Subsequently, at the beginning of ebb this near-surface water is advected back over the salt wedge, it is then followed by freshwater with higher near-surface SPM concentrations from up-estuary. The time evolution of this along-channel near-surface SPM concentration distribution is governed by vertical shear advection at late flood (Figs. 8 and 11) and settling of SPM over the salt wedge (Figs. 8, 9, and 10) during the flood period due to turbulence damping at the pycnocline (Geyer 1993). The latter phenomenon is identified by a decrease of SPM concentrations above the saltwater layer with seaward distance from the limit of saltwater intrusion and higher 

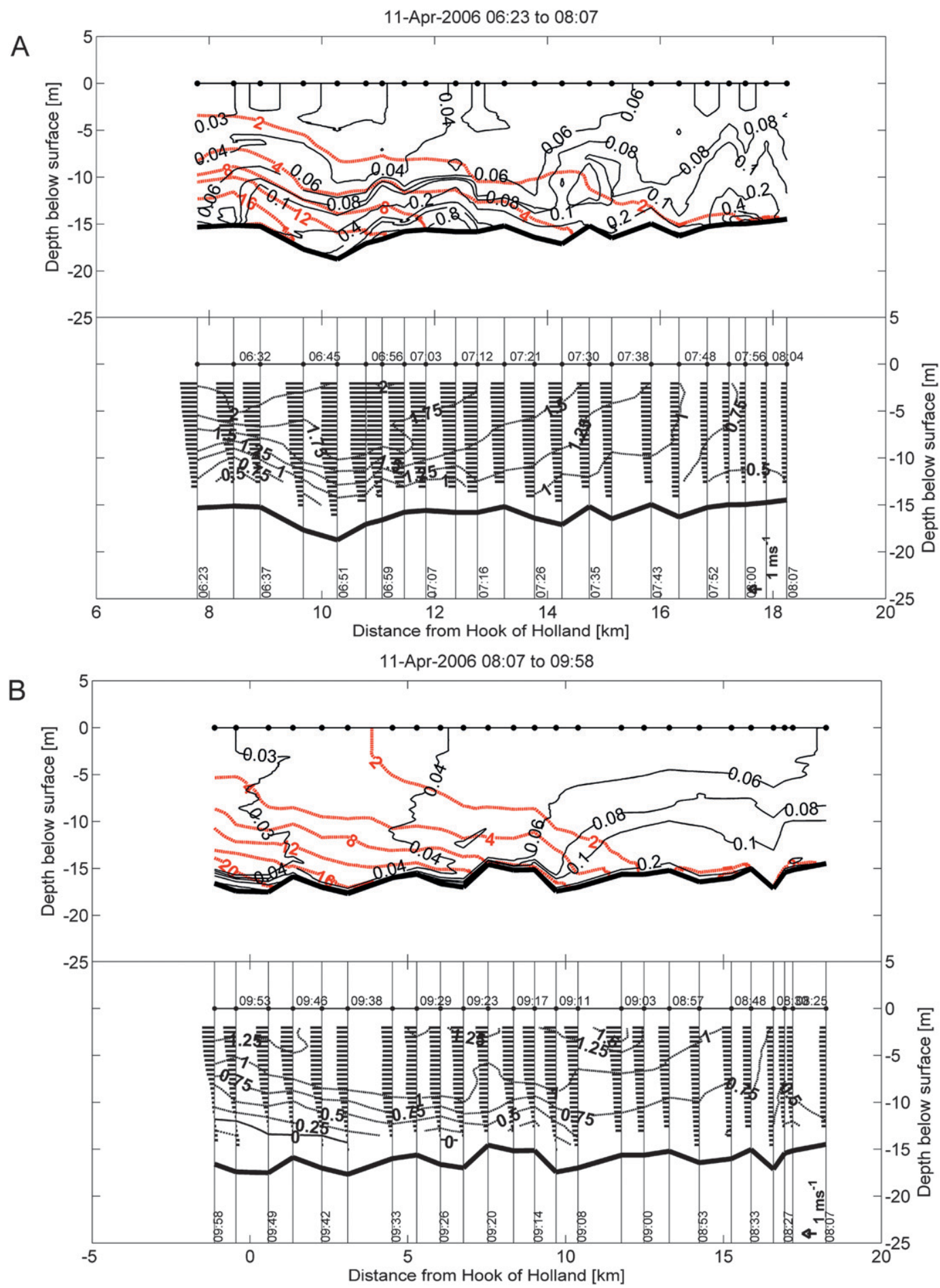

FIG. 8. The along-channel and vertical distribution of (top in each set) salinity (dashed lines) and SPM concentration (continuous lines) and (bottom in each set) primary velocity component (negative $=$ ebb flow) indicated by the contours and profiles constructed from passages through the head of the salt wedge; A to J refer to transects 1 to 10, respectively: 11 Apr 2006 (a) 0600-0807 (b) 0807-0958, (c) 1147-1251, (d) 1258-1400, (e) 1604-1701, and (f) $1701-1828$. 

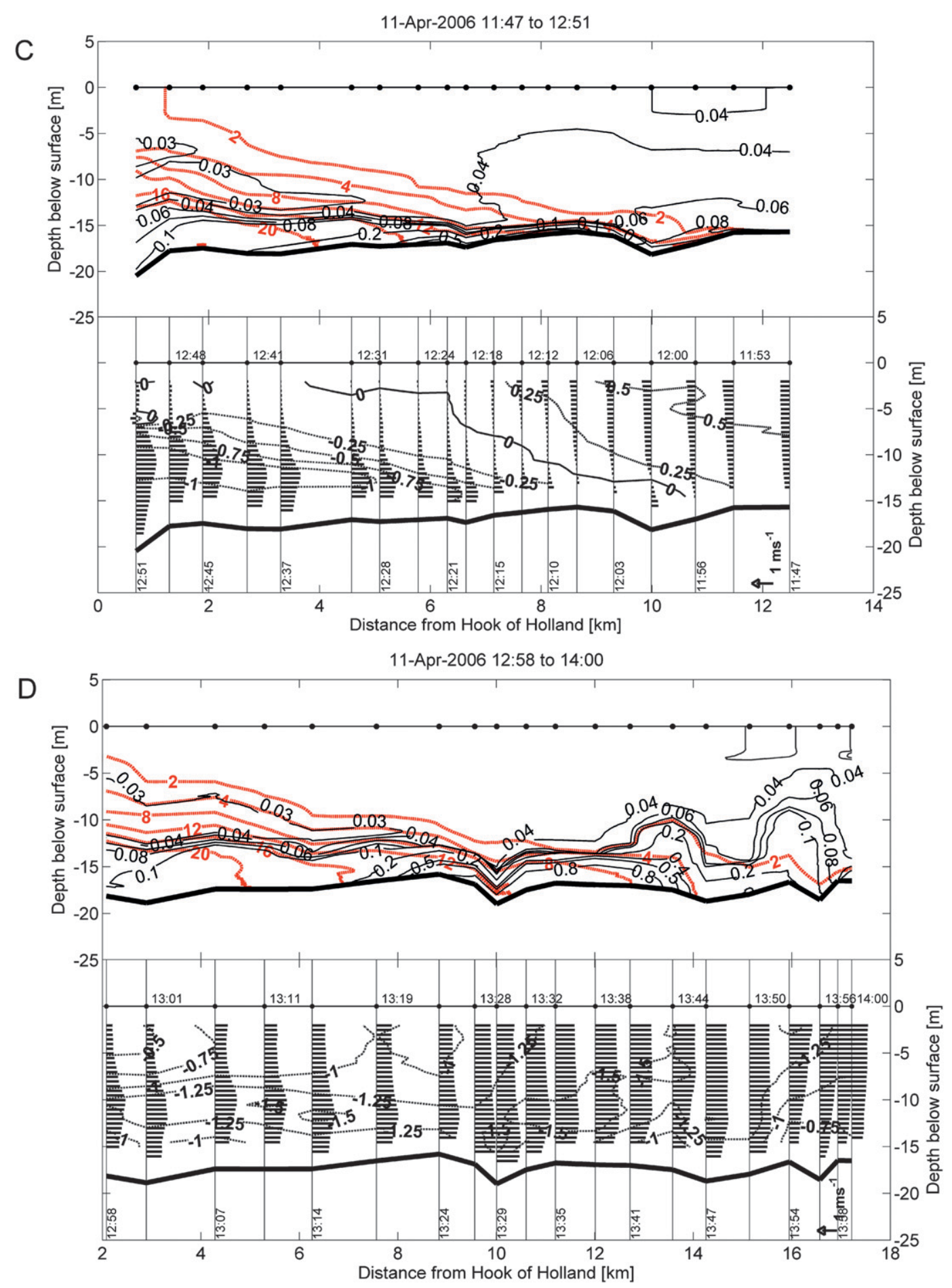

FIG. 8. (Continued)

near-surface SPM levels during ebb above the salt wedge than at flood (Figs. 8, 9, and 10).

At slack water, the ETM temporarily loses part of its SPM because of deposition caused by the low turbulent mixing rates (Fig. 8 from 0900 to 1200 and Figs. 9, 10, and
11). This results in the formation of fine sediment layers on the sandy bed. The observations never showed nearbed concentrations above a few tenths of kilograms per meter cubed, although inside the ETM concentrations of about $1 \mathrm{~kg} \mathrm{~m}^{-3}$ have been measured during the flood 

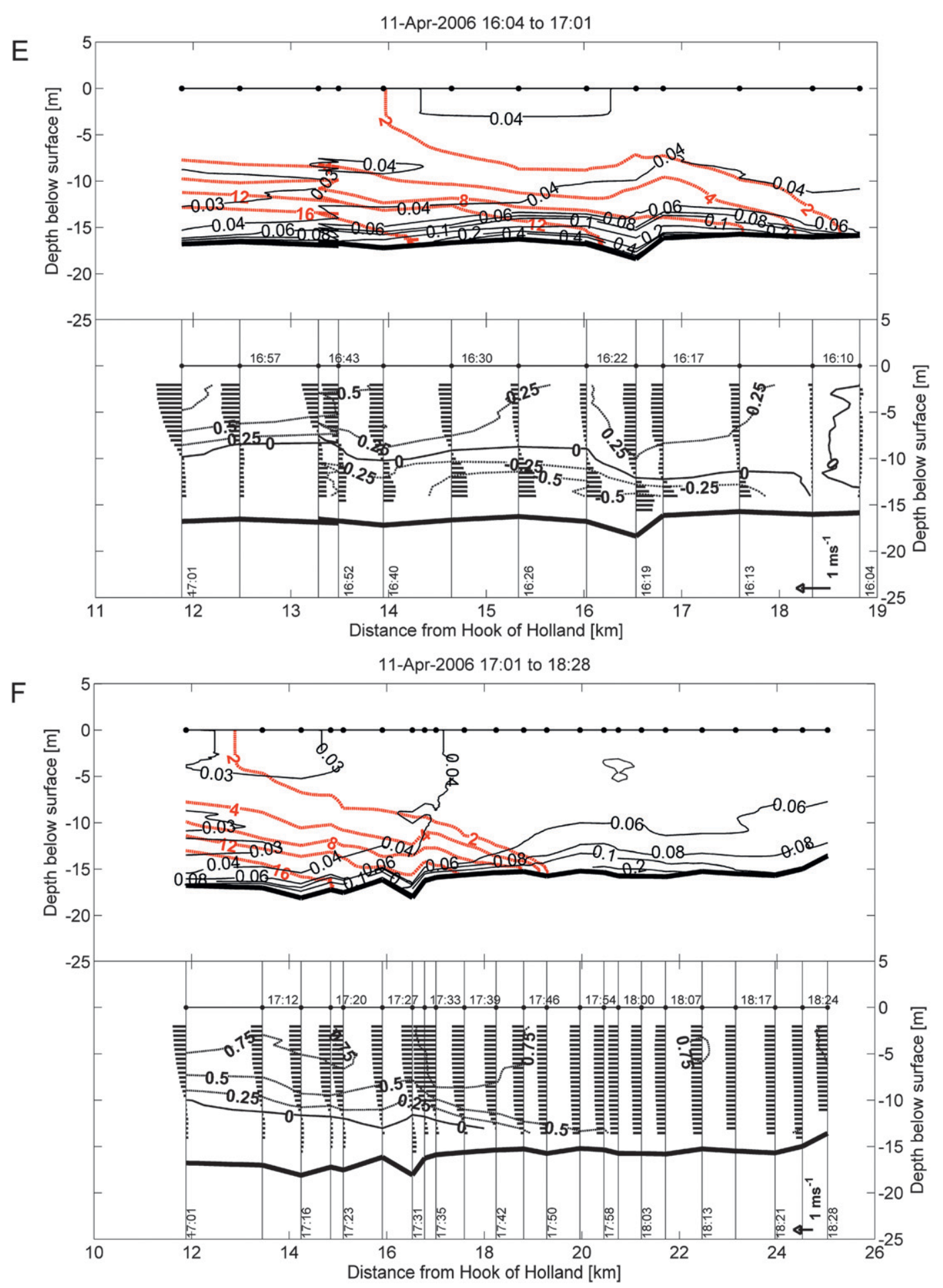

FIG. 8. (Continued)

period. However, it is estimated that these high SPM concentration layers are only a few centimeters thick at slack water, which makes them undetectable with our instrumentation. Entrainment of SPM from the bed during the beginning of flood and ebb prevents permanent storage in the bed. It is therefore anticipated that the total deposition around slack tide equals the subsequent total resuspension during flood and ebb. At the down- and up-estuary stations, peak SPM concentrations occur before peak velocities (see Figs. 2 and 4; 


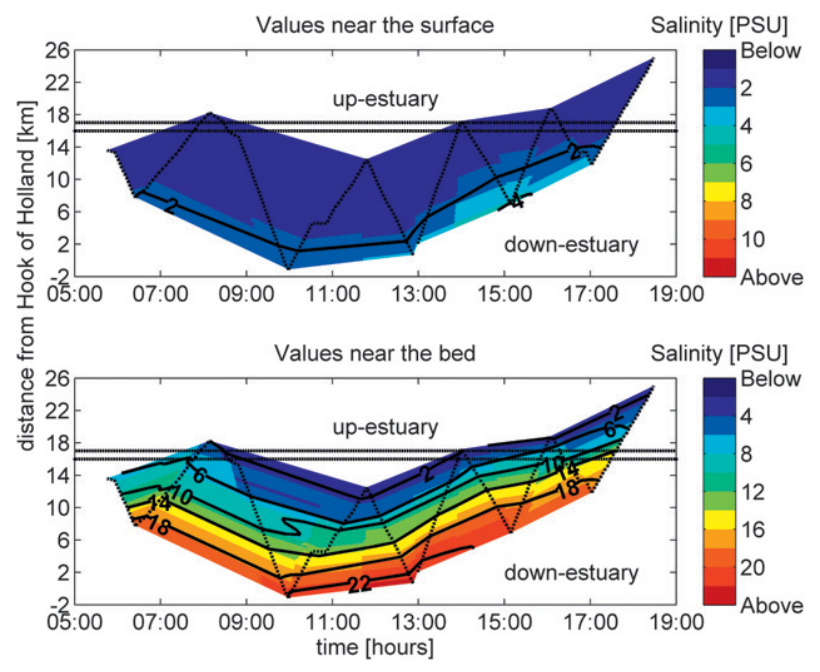

FIG. 9. Along-channel distribution of salinity in (top) a nearsurface layer and (bottom) near-bed layer during the survey on 11 Apr 2006 showing the evolution of the along-channel distribution in time. If one draws a vertical line between these figures, at a specific time, one sees the interpolated values of the alongchannel distribution at that time. The ordinate ranges from $-2 \mathrm{~km}$ (close to the mouth of the Rotterdam Waterway) to $26 \mathrm{~km}$ inland. The dashed lines show the location of the Botlek Harbor $(\sim 16 \mathrm{~km}$ inland), and the junction Rotterdam Waterway-New Meuse-Old Meuse $(\sim 17 \mathrm{~km}$ inland). The dashed-dotted lines in both graphs depict the navigated transects. Note the different salinity scales.

stations 1 and 7, not shown). This indicates that the tidal potential entrainment-erosion rate exceeds the availability of sediment at the bed (see also appendix). These (bed) conditions indicate that SPM transport and entrapment are not determined by peak velocity and mixing asymmetries, but are more sensitive to slack water period asymmetries, lag effects, and processes driven by the baroclinic pressure gradient and buoyancy forces such as the formation of exchange flow profiles and turbulence damping. Furthermore, frequent exchange of SPM between the ETM and harbor basins limits accumulation of SPM in the ETM, and consequently a bedbased supply of mud is not formed.

When sediment induced resuspension lags occur after LWS, the pycnocline still damps turbulent diffusion of SPM over the entire water column. However, this may not be the case after HWS when saltwater has been advected down-estuary or when stratification of the remaining saltwater may be too weak to damp turbulent mixing. Therefore, a sediment particle travels on flood below the pycnocline (Figs. 9, 10, and 2; station 2 from 1200 to 1700) and travels back during ebb higher in the water column, lagging the retreat of the salt wedge (Fig. 2; station 2, SPM cloud 1 from 0600 to 0730 and cloud 2 from 0700 to 1100). The measurements indicate that such an SPM patch, or at least part of it, can eventually

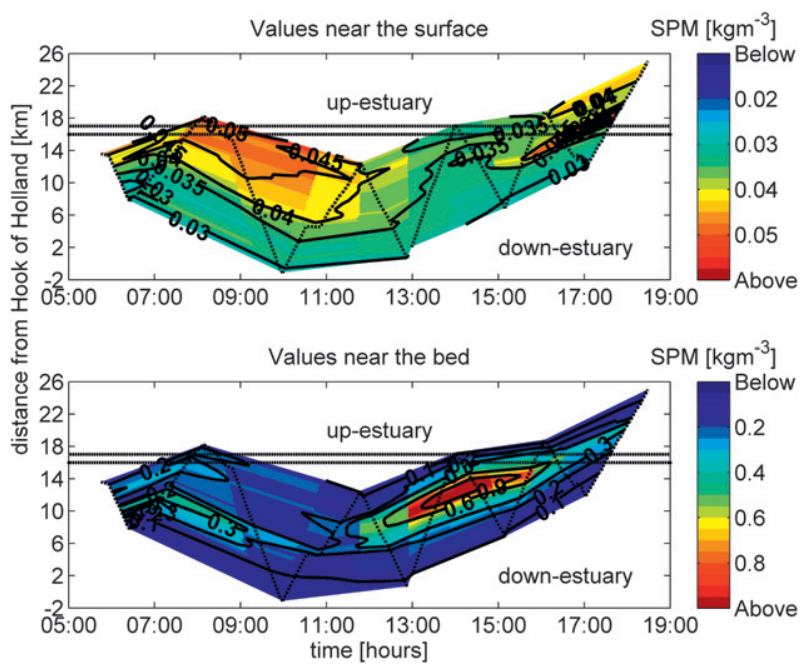

FIG. 10. Along-channel distribution of SPM concentration in (top) a near-surface layer and (bottom) near-bed layer (second graph) during the survey on 11 Apr 2006. The dashed lines in both graphs depict from bottom to top the Botlek Harbor and junction Rotterdam Waterway-New Meuse-Old Meuse, respectively. The dashed dotted lines in both graphs depict the navigated transects. Note the different SPM concentration scales. The ETM is defined as the region with high SPM concentrations. The threshold is arbitrarily set at the SPM $0.10 \mathrm{~kg} \mathrm{~m}^{-3}$ contour line. The length of the ETM varied intratidally due to exchange with the bed (resuspension-settling), longitudinal velocity gradients during advection periods and geometrical effects (such as exchange with the basins and bifurcation at the junction Rotterdam Waterway-New Meuse-Old Meuse). It reached a maximal length of about $10 \mathrm{~km}$ (see also Fig. 6, transects 7, 8, and 9), which is smaller or comparable to its tidal excursion length. The two clouds of SPM in the lower layer at $\sim 0600-0900$ can be easily identified, as can the layer of fresher, sediment laden, water that sits above saline waters with a lower SPM concentration on the ebb from approximately 0800 to 1100. Moreover on flood a somewhat different response is observed, with larger concentrations of SPM being advected by the salt wedge (1300-1600), whereas the waters above the pycnocline are low in SPM. However around HWS, SPM has settled from the lower layer, but two distinct patches of SPM are observed at kilometer 14-22 in the upper layer.

be recollected in the saltwater layer around LWS (Figs. 9 and 10).

\section{c. Tidally averaged budgets and ETM generation time scale}

To analyze the efficiency of the SPM trapping processes we define a balance area (Fig. 12). These processes cause a difference in the seaward-directed tidally averaged SPM transport between the up- and down-estuary borders, which is larger than the exchange of SPM with the Botlek Harbor basin (Table 1). The tidally averaged salinity and SPM transport profiles show up-estuary transport in the lower layer at the down-estuary boundary of the balance area (station 1) and down-estuary 


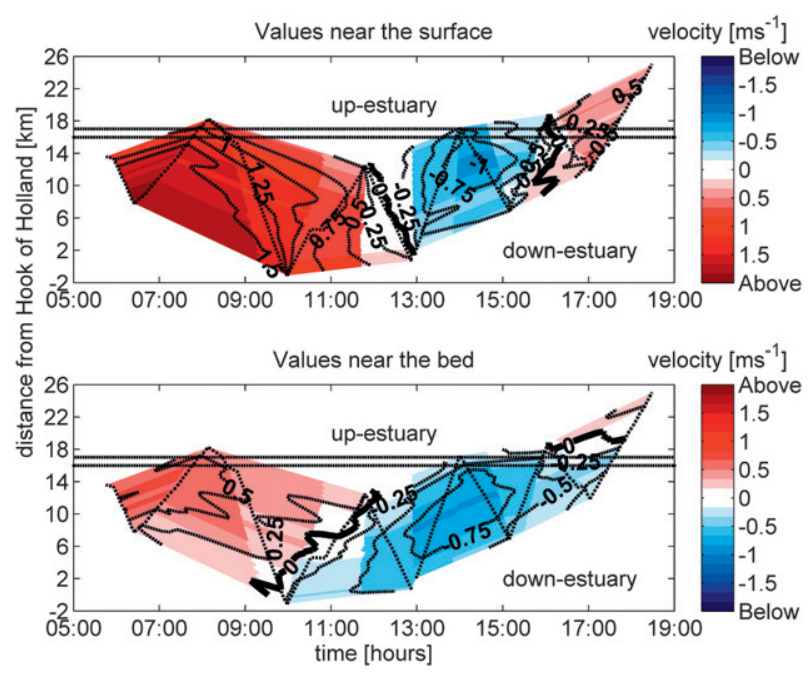

FIG. 11. Along-channel distribution of the primary (along channel) velocity component (negative $=$ flood) in (top) a nearsurface layer and (bottom) near-bed layer recorded during the survey on 11 Apr 2006. The dashed lines depict (bottom to top) the Botlek Harbor and junction Rotterdam Waterway-New MeuseOld Meuse. The dashed dotted lines depict the navigated transects. Note the formation of fronts around $0900-1200$ and 1600-1800. These hydrodynamic features are associated with near-bed convergent transports and differential advection. If one draws a vertical line, between the upper and lower water column figures at, for example, 1100 differential advection is evident; while the angle of the slack water lines at bottom indicates convergence.

transport over the water column at the up-estuary boundaries (stations 6 and 7). Thus, salinity and SPM transports converge in the lower layer in a tidal average sense, and therefore the amount of SPM in the balance area and thus in the ETM at the head of saltwater increases (Table 1, row 3 minus rows 2 and 4). Based on this difference in SPM transport the yearly accumulation rate of SPM in the Rotterdam Waterway is estimated at 1.5 $\mathrm{Mt} \mathrm{yr}^{-1}$ (Table 1, column 4, rows 2 and 3). Table 1 shows that the amount of SPM transported on flood and ebb at station 2 in the middle part of the estuary is larger than at the stations in the upper and lower estuary stations (columns 2 and 3, cf. rows 2-4 with row 5). The fact that this yearly accumulation rate is of the same order as the yearly sedimentation rates of fine-grained sediments (mud) in the harbor basins along the Rotterdam Waterway and New Meuse (i.e., including the Botlek Harbor) indicates the importance of the role of the ETM in the siltation process of the up-estuary harbor basins along the Rotterdam Waterway and New Meuse and vice versa (see De Nijs et al. 2009).

The time scale for the redevelopment of ETM to its original state, after its hypothetical removal, is estimated from the total amount of SPM displaced during the flood period at Station 2, and the net supply. This time scale amounts to 3 tidal periods. Based on exchange measurements in the Botlek Harbor mouth on 11 April 2005 , it is assessed that about one-seventh of the total amount of SPM in the ETM is transported into the Botlek Harbor during a tide-the trapping efficiency of the Botlek Harbor is almost $100 \%$ (De Nijs et al. 2008b). Hence, it acts as an efficient sink for SPM in the ETM.

\section{d. Dispersive fluxes}

The instantaneous and tidally averaged fluxes from the mass transport decomposition analysis are shown in Figs. A1 and 13, respectively. The tidally averaged discharge (TT1; left-pointing open triangle symbol) is the dominant mechanism conveying SPM and salinity seaward; it is almost $100 \%$ of the export at every station. At station 1, tidal pumping (TT3 and TT4; open diamond and open square symbols, respectively) and gravitational

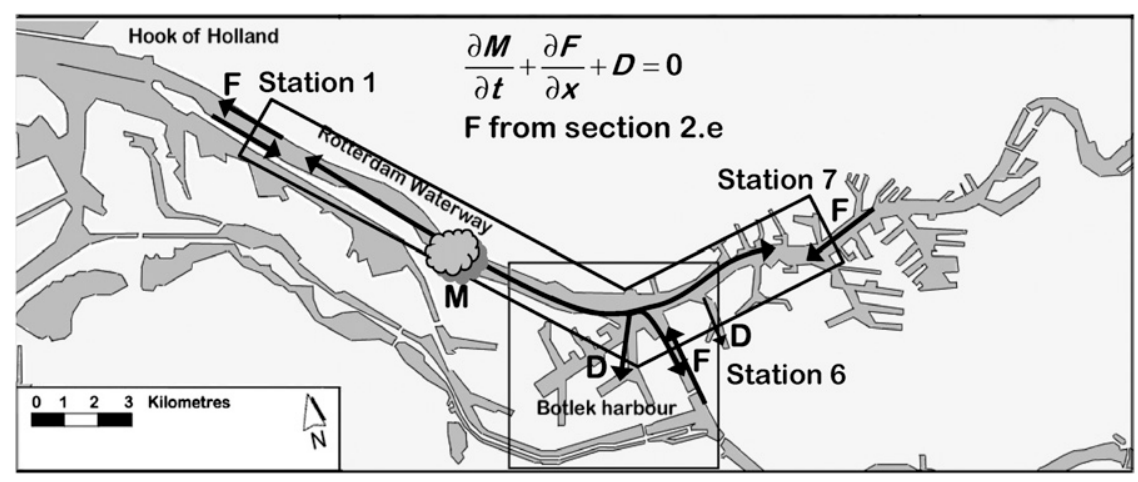

FIG. 12. Balance area of the ETM measured during the survey on 11 Apr 2006. Stations 1, 6, and 7 define the borders of a domain used to estimate the tidal time scale of transport of salt and sediment. These transports are used to quantify the SPM budget in the ETM over a tidal cycle, the generation time scale of the ETM, and the physical processes that contribute to the horizontal transport of SPM. 
TABLE 1. SPM budget in the ETM over a tidal cycle based on data collected on 11 Apr 2006 at stations 1, 2, 3, and 7, and data collected on 14 Apr 2005 in the mouth of Botlek Harbor. Total SPM fluxes during a part and complete tidal cycle. Positive values denote a downestuary-directed SPM flux or a sink flux. It is noted that the current, salt, and SPM concentration structure has been measured at three points in a cross section. It is therefore emphasized that the fluxes and quantities in Table 1 are approximations. At all stations the net tidally and depth-averaged sediment transport is directed seaward. Landward transport is only observed at stations 1 and 2 in the near-bed part of the tidally averaged SPM transport profile (not shown). This up-estuary transport at station 2 is attributed to exchange of part of the SPM in the ETM from the Rotterdam Waterway into the Botlek Harbor, but relative motion between salt and turbid water also contributes to this observation.

\begin{tabular}{lccc}
\hline \multicolumn{1}{c}{ Stations } & Up-estuary (tons per flood) & Down-estuary (tons per ebb) & Net (tons per tide) \\
\hline Station 1 (down-estuary border) & -3640 & 5030 & 1390 \\
Station 6 (up-estuary border) & -1800 & 3000 & 1200 \\
Station 7 (up-estuary border) & -1730 & 3990 & 2260 \\
Station 2 & -6090 & 8050 & 860 \\
Botlek Harbor (sink) & & & \\
\hline
\end{tabular}

circulation (TT5; right-pointing open triangle symbol) contribute predominantly to the landward SPM flux, $15 \%, 15 \%$, and $70 \%$, respectively. Tidal pumping is the dominant SPM flux mechanism at the up-estuary stations $(2,3,5$, and 6$)$. At station 2 the contributions of tidal pumping and the gravitational circulation are $15 \%, 55 \%$, and $30 \%$ respectively. Station 7 is outside the excursion range of saltwater and ETM. Here the landward transport by tidal pumping was $19 \%$ of the seaward directed transport by the tidally averaged discharge. Landward transport by tidal pumping is counteracted by the tidally averaged seaward directed discharge, and therefore it does not play a role in maintaining a stable ETM up-estuary of the saltwater.

If we compare the distribution of the aforementioned terms at a particular station (stations 1,2,3,5, and 6) for salinity (upper two panels) and SPM (lower two panels) there is a strong correlation. The salt wedge and ETM have been advected through stations 2, 3, 5, and 6 during both ebb and flood. This suggests that advection of both the salt wedge and ETM structure determines the SPM transport terms, not local processes (see also the appendix). At stations 1, 2, 3, 5, and 6 the tidal depth mean transport (TT4) also contributes to landward transport of saltwater. Although, this may reflect some uncertainty, this type of transport can be attributed to tidal pumping by the diurnal inequality; that is, the net import of salinity over a semidiurnal time scale associated with the tidal asymmetrical displacement of the salt wedge due to differences in subsequent low water levels (see De Nijs et al. 2010). This means that tidal pumping by the diurnal inequality contributes to the TT4 SPM flux as well.

\section{e. SPM origin and budgets}

One of the key questions is how SPM is supplied to the ETM. This involves the determination of the relative contribution of marine and fluvial sediment sources from long-term sediment budget and tracer analyses (see De Nijs 2011). The results of tracer analyses indicate that the major constituent in the harbor basins along the Rotterdam Waterway is fluvial sediment, about $90 \%-100 \%$. Based on sediment balances that cover the period 1977-2000, it is established that the annual fluvial SPM influx exceeds the siltation rates of the channels and harbors along the Rotterdam Waterway and New Meuse. Hence, although the salinity induced density structure keeps SPM in the estuary, the Rotterdam Waterway does not function as a complete fluvial SPM trap (see also Table 1, row 3 minus row 2). About $50 \%$ of the annual fluvial SPM flux at the junction is allowed to escape the Rotterdam Waterway. Tracer analyses and reanalysis of older tracer studies confirm this picture, sediments of fluvial origin, $\sim(10 \%-25 \%)$, are found down-estuary in the Maasmond (Europoort and Caland-Beerkanaal).

The siltation rates at Botlek Harbor and the downestuary border the Maasmond do not significantly correlate. The siltation rates at Botlek Harbor are commonly high, while siltation at the Maasmond is determined by events (Verlaan and Spanhoff 2000). At both areas the siltation rates show seasonal variation. The siltation rates at Botlek Harbor are generally higher from winter to spring (freshets) compared to the summer and early autumn. At the down-estuary border, the Maasmond, high siltation rates particularly occur from autumn to winter during and after rough weather periods and associated high wave activity on the North Sea. The magnitude of these siltation events indicates a marine source (Verlaan and Spanhoff 2000).

When sedimentation events occur at the Maasmond, marine sediments enter this Port system mainly as nearbed suspensions (Kirby and Parker 1977; Vlemmix 1980; Kirby 1992; van Woudenberg 1998). The Maasmond area is much deeper than the Rotterdam Waterway, which prevents these near-bed marine suspensions from propagating into the Rotterdam Waterway. Therefore, 


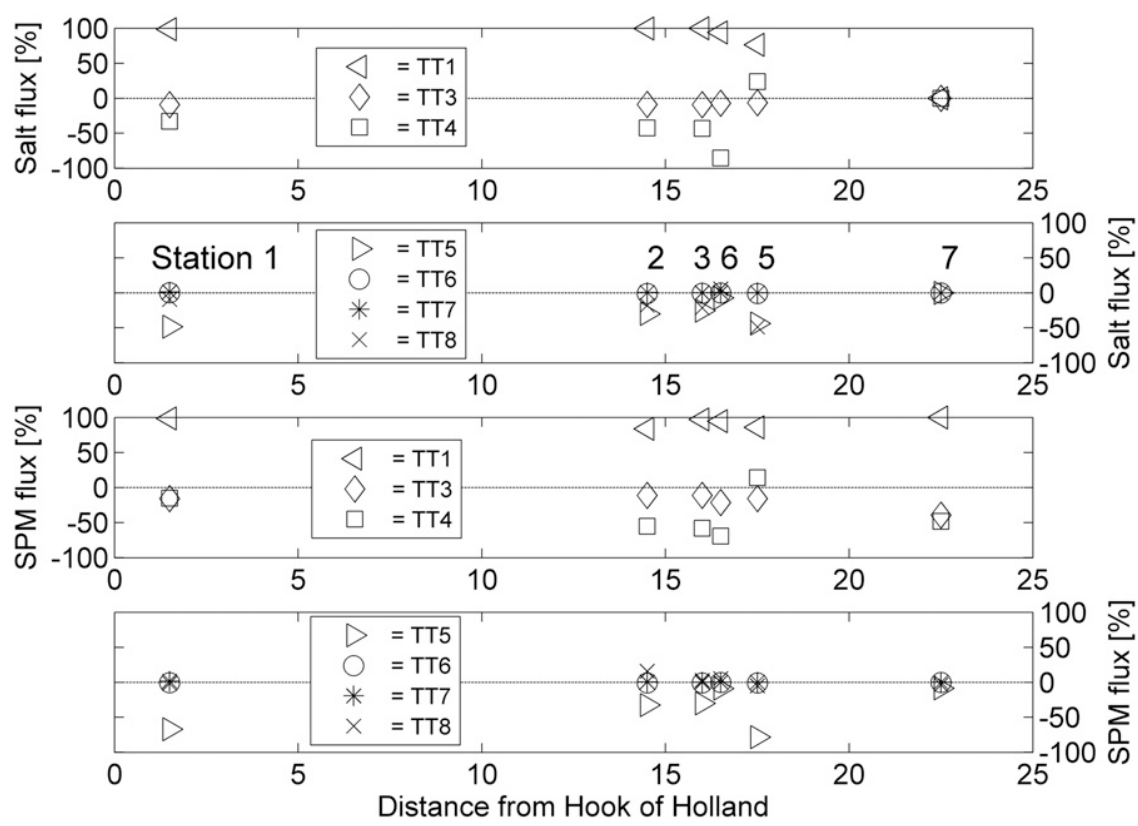

FIG. 13. The computed terms in the decomposition of the mass transports for the tidal and cross-sectional- averaged salinity and SPM transport per unit width [Eq. (3) terms TT1TT8]. The terms have been obtained from a decomposition of the instantaneous vertical velocity and SPM profiles recorded at stations 1-3 and 5-7. (top and top middle) Depth mean (advection) and shear-induced dispersion transport components of salinity, respectively. (bottom middle and bottom) The depth mean (advection) and shear-induced dispersion transport components of SPM, respectively. Positive values indicate net seaward transport. The locations of stations $1,2,3,5,6$, and 7 are shown in the second panel from the top.

the tidal and shear SPM transport terms at station 1 may not be interpreted as import of marine SPM, but rather ascribed to the recirculation and advection of accumulated fine sediment, which most likely is mainly of fluvial origin.

Based on data from yearly bed sample campaigns collected by the Port Authority, (see De Nijs 2011), it is established that the dredged material in the Rotterdam Waterway, New Meuse, and Old Meuse predominantly consists of fine and medium sand hardly any mud is dredged, while the dredged material in the harbor basins along the Rotterdam Waterway and New Meuse mainly consists of fine sand and mud. This indicates that the harbor basins provide efficient fluvial SPM traps as a result of which no permanent bed source of mud in the Rotterdam Waterway, New Meuse, and Old Meuse can develop.

The large river discharge gives rise to a large fluvial SPM flux, although the background river SPM concentrations are low (about $0.030 \mathrm{~kg} \mathrm{~m}^{-3}$ ). Therefore the background SPM concentration gradients are relatively weak; that is, the background SPM concentrations (Fig. 2) amount to $0.015 \mathrm{~kg} \mathrm{~m}^{-3}$ at station 1 and $0.030 \mathrm{~kg} \mathrm{~m}^{-3}$ at stations 6 and 7 (not shown).

\section{Discussion}

SPM accumulation at the head of the salt wedge in the Rotterdam Waterway is not determined by the magnitude of velocity and turbulent mixing asymmetries (e.g., van Leussen and van Velzen 1989; Jay and Musiak 1994; Burchard and Baumert 1998; Chant and Stoner 2001; Scully and Friedrichs 2003) but rather by trapping processes driven by the salinity-induced density structure operating at the head of the salt wedge. A schematic highlighting these processes is presented in Fig. 14. It is the combination of barotropic tidal asymmetry imposed at the mouth, baroclinicity and suppression of turbulence at the pycnocline that determines the flow structure in the Rotterdam Waterway (De Nijs et al. 2010). These processes act to trap fluvial sediments that are in suspension in the fresher, upper parts of the water column into the layer beneath the pycnocline. In fact, turbulence damping at the pycnocline operates throughout the tidal cycle, and hence the SPM above the pycnocline can settle throughout the tidal cycle slowly clearing the water column from SPM. The baroclinic pressure gradient and decoupling effects associated with damping of 

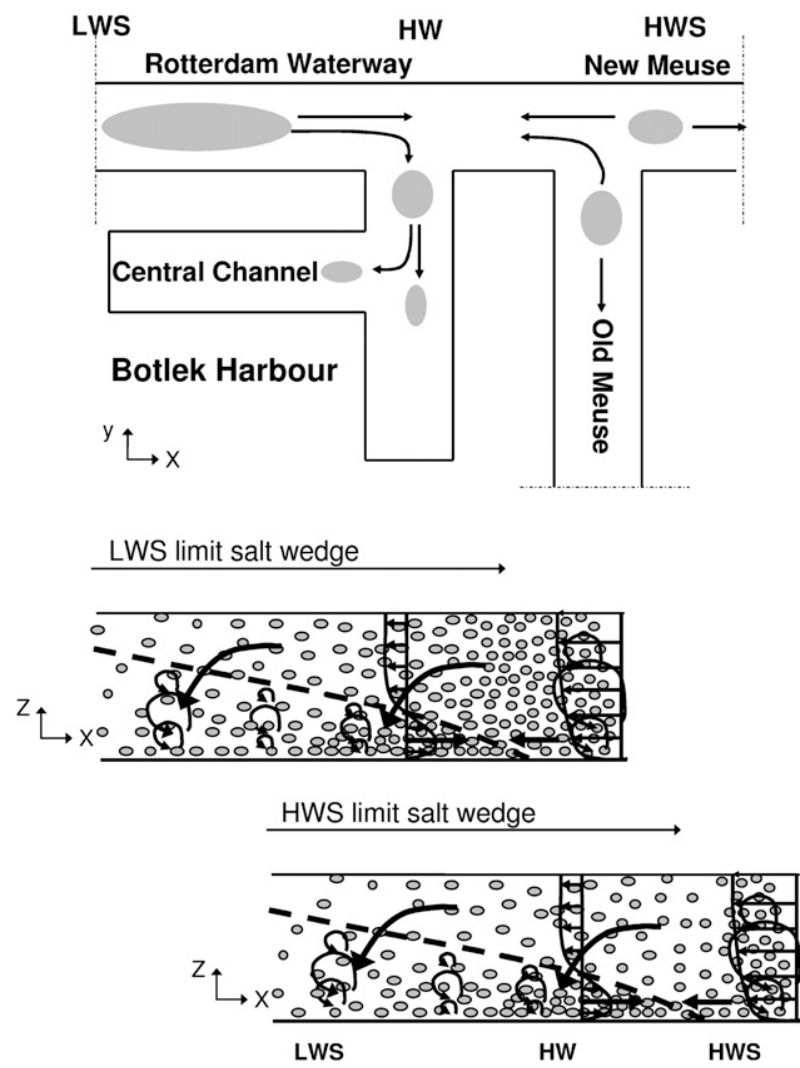

FIG. 14. (top) A conceptual sketch of along-channel exchange flows at LWS and HWS, which depict differential advection and frontal convergence. SPM becomes trapped near the limit of saltwater because of near-bed converging SPM transports and SPM advected over the saline water front settles because of turbulence damping at the pycnocline. At LWS freshwater with relatively more SPM is advected over the salt wedge than at HWS. At HWS, SPMladen water, which has been above the salt wedge during flood is first advected back over the wedge followed by fresher water with more SPM. (bottom two panels) A conceptual Lagrangian sketch of the relation between sediment entrapment in the Rotterdam Waterway and harbor siltation under typical hydrodynamic conditions. (bottom panel) Patches indicating elevated SPM concentrations advancing and retreating with the head of the salt wedge on a semidiurnal time scale. During flood, tide saline and turbid water exchange with the harbor basin and bifurcate at the junction into the New Meuse and Old Meuse and are advected back into the Rotterdam Waterway during ebb tide, but at different phases of the tide. The length of the ETM is smaller than or about equal to the tidal excursion length. Therefore, the length scale within which high sediment concentrations occur is smaller than the advection length scale. This highlights the importance of nonuniformity of the alongchannel SPM distribution (gradients) and advection.

turbulence at the pycnocline induce vertical velocity shear during the ebb tide, which favors differential advection of SPM over the salt wedge and retards near-bed currents toward LWS. The latter results in near-bed longitudinal transport gradients, directed into the salt front, which indicate horizontal trapping.
At the head of the salt wedge near LWS, the baroclinic pressure gradient drives a flood current near the bed, which in turn entrains and transports SPM against the ebbing current, which causes the observation of exchange flows (Fig. 14). These exchange flows indicate near-bed convergence of transports and relative motion between salt and freshwater layers, both processes contribute to SPM trapping near the limit of saltwater intrusion. Because of the latter process, fresh SPM laden water is advected over the pycnocline. However, as a consequence of damping of turbulent mixing by stratification at the pycnocline, the SPM then starts to settle into the lower, more saline layer beneath. The effect of turbulence damping on SPM entrapment is indicated by a distinct seaward decrease of SPM above the salt wedge. The trapped SPM is recirculated and advected by currents driven by the baroclinic and barotropic tidal pressure gradients. This is in agreement with the dispersive flux analysis, which shows the dominant contribution of the gravitational circulation and minor contributions by tidally changing shear and stratification correlations associated with baroclinic shear flows (appendix; De Nijs et al. 2010) and internal tidal asymmetry (e.g., Jay and Musiak 1994, 1996) to up-estuary transport of salt and SPM (see station 1). Furthermore, the dispersive flux analysis shows that barotropic tidal asymmetry, in combination with sediment induced threshold lags cannot maintain an SPM balance against the river flow (see station 7).

However, barotropic asymmetry imposed at the mouth of the Rotterdam Waterway does have a role to play. It imposes a time scale on the advection of the salt wedge and determines the barotropic asymmetries within the estuary. It arises from the nonlinear deformation of the tidal wave in the shallow North Sea, before entering the estuary. A detailed analysis by De Nijs et al. (2010) found that internal tidal asymmetry, has a negligible role to play within the Rotterdam Waterway. This is in contrast to the Columbia River, which is connected to a deep, narrow offshore shelf. Jay (1991) and Jay and Musiak (1996) found a less distinct barotropic $M_{4: U}$ overtide component near the mouth of the Columbia River. Therefore, the mechanism presented here (Fig. 14) is likely to operate in narrow, partially mixed and stratified estuaries, with relatively strong river runoff, which border shallow shelf seas with relatively strong barotropic tidal forcing.

Although there is a distinct barotropic tidal asymmetry, the measurements presented here provide support to the mechanism first proposed by Geyer (1993). He clearly shows the important role played by turbulence damping, at the pycnocline, in the raining out and subsequent trapping of fluvial sediment. However, here 
we also show that the mechanism operates in a reference frame moving with the salt wedge, throughout both the flood and ebb. The observations show a distinct spatial variation in the current structure and turbulent mixing, which is driven by the baroclinic structure. Furthermore we demonstrate that it is this spatial variation that is responsible for the trapping of fluvial SPM that is in suspension.

The magnitude of the SPM concentration and distribution is determined by the limited availability of SPM (mud) at the bed, advection of the salt wedge and associated ETM, and dynamics of the SPM in the ETM relative to saltwater due to deposition, resuspension, and exchange with harbor basins and side channels. The SPM in the ETM near the head of the salt wedge undergoes a cycle of processes, which include advection, settling, and entrainment before this SPM is transported into areas of low hydrodynamic energy, such as harbor basins. Sediment particles follow complex pathways, which include vertical excursions between the salt and freshwater layers because of relative motion between the saline and turbid water. After HWS relative motion between saline and turbid water causes the temporary separation of part of the SPM from the ETM below the pycnocline. This SPM lags behind the saltwater because of settling and resuspension. Hence, relative motion between saline and turbid water favors the transport of SPM beneath the pycnocline on flood and above it during ebb. This SPM patch will eventually accumulate again in the saltwater layer. Relative movement between salt and turbid water will not result in the accumulation of finegrained sediment landward of the saltwater intrusion because the relatively large, seaward-directed, tidally averaged discharge counteracts the up-estuary transport by tidal pumping (see station 7, Fig. 13).

The bed conditions determined from bed samples (section 3e) and SPM measurements indicate that all fine sediment settling on the bed is in suspension during ebb-flood advection periods. This indicates that deposition at HWS approximately equals entrainment after HWS and that, subsequently, deposition at LWS approximately equals entrainment after LWS. In fact, the entrainment capacity appears more than sufficient to remobilize the available fine sediments for transport. Furthermore, the transport conditions indicate that the transport carrying capacity (Fig. 7) is not fully utilized (see also De Nijs et al. 2008; De Nijs 2011). Hence, the ETM behavior is not largely affected by a bed supply of mud. It is noted that this observation contrasts with many studies on accumulation of SPM. Those studies show either temporary (during neap) or permanent storage of mud in the bed. In such cases, SPM transport is determined by the magnitude of velocity asymmetries.
The origin of the sediment in the Rotterdam Waterway lends further support to the mechanism summarized in Fig. 14. It is concluded that the absence of a bed-based supply of mud in the Rotterdam Waterway can be attributed to the continuous removal of fine sediment from the system by sedimentation in the harbor basins and subsequent dredging operations, where the dredged sediments are deposited elsewhere (e.g., the North Sea). Moreover, this system is too dynamic and it does not function as a complete fluvial SPM trap because of excursions of saltwater. Therefore, relatively sharp transitions between sandy (Rotterdam Waterway, Old Meuse, Hartelkanaal, and New Meuse) and muddy beds (harbors) occur in spite of a relatively large supply of fluvial mud. The ETM persists despite the absence of a significant marine source of SPM because it is maintained by trapping of a relatively large fluvial supply of SPM.

Eisma et al. $(1980,1991)$ found no evidence of saltinduced flocculation in the Rotterdam Waterway. An analysis of sediment particles showed that these were already aggregated by organic matter in the freshwater region (see also Santema 1953). Dyer et al. (2002) and van Leussen (1994) indicate that the flocculation processes in high energetic estuarine systems are largely determined by parameters such as SPM concentration and shear rate. However, an increase in settling of SPM due to aggregation processes as found in high energetic estuarine systems on the time scale of the observation(s) is unlikely. These quantities are low above the pycnocline, and the SPM concentration decreases seaward (Figs. 8 and 10). The flocculation process in the upper part of the water column is therefore expected to have a relatively large time scale (van Leussen 1994).

The mechanism presented in Fig. 14 implies hydrodynamic sorting of SPM near the surface along the estuary axis. Past studies (Eisma et al. 1980, 1982, 1991; van Leussen 1994, p. 60: Eisma et al. 1982) provide support for this. They observed a gradual seaward increase in the percentage of fine aggregates and decrease in the percentage of large aggregates (macro flocs) in particle size distributions near the surface. Higher levels of organic matter were also found in the saltwater region at low salinities. This suggests the effects of the production of small scale turbulence in areas of high shear rates around the pycnocline (Fig. 8; De Nijs 2011), which break up fragile macro flocs.

Note that we may not use a single near-bed monitoring station (van Leussen and van Velzen 1989) to determine net transport rates, in situations in which flood transport is concentrated near the bed and ebb transport is more homogenously distributed over the water column. However, differences in ebb and flood transport in the Rotterdam Waterway can already be explained by the 
exchange of part of the ETM with the harbor basins (De Nijs et al. 2009). Furthermore, the effects of advection and water-bed exchange processes cannot be distinguished from such single monitoring stations either. For example, over the spring neap cycle the distance of the saltwater intrusion limit and ETM relative to the mooring changes. This causes variations in SPM concentration which are driven by (asymmetrical) displacements rather than by local processes (erosion, resuspension). Consequently, near-bed moorings alone cannot give complete insight in these processes, nor serve as a dataset to properly test and validate three-dimensional models.

The key to understanding the mechanisms contributing to ETM formation in the Rotterdam Waterway is that there is no bed-based supply of mud, the transport capacity is not fully utilized and that the SPM in the ETM is predominantly of fluvial origin. The harbor basins along the Rotterdam Waterway and New Meuse provide efficient SPM sinks and the Rotterdam Waterway is not a complete fluvial SPM trap. Even though background SPM concentrations on the river are relatively low, the strong regulated river discharge gives rise to a large fluvial SPM flux that exceeds the siltation rates of the harbor basins along the Rotterdam Waterway and New Meuse. Hence, the fluvial SPM flux is sufficient to maintain the ETM over time and on subtidal time scales the SPM trapping efficiency depends on the salt intrusion length.

Therefore, we have a mechanism for ETM formation, which is in contrast with the maintenance mechanism suggested by Jay and Musiak (1994) and Burchard and Baumert (1998). These authors emphasize the importance of baroclinic and turbulent mixing induced asymmetry and spatial variation of near-bed currents. It also contrasts with concepts of landward transport based on baroclinic driven tidal asymmetries in bed shear stress (van Leussen and van Velzen 1989) and the resuspension height of sediment (Scully and Friedrichs 2003). Moreover, it is different to the mechanism discussed by Chant and Stoner (2001), they emphasize the combined effect of (flood dominated) barotropic tidal asymmetry and buoyancy on turbulent mixing which drives an asymmetry in sediment deposition and resuspension augmenting particle trapping in the Navesink River estuary. However, any (partially) stratified estuary experiences a reduction of turbulence at the pycnocline throughout the tidal cycle, and will result in the raining out and trapping of fluvial SPM from the saltwater layer. In consequence, the mechanism presented here, Fig. 14, should have broader implications (see Geyer 1993).

Acknowledgments. This research is supported by the Dutch Technology Foundation STW, Applied Science Division of now, and the Technology Program of the
Ministry of Economic Affairs. The authors thank the Port of Rotterdam, in particular Herman Meijer, for giving support to this research and for providing vessels and crews to conduct the boat survey. Marc Rotsaert of Port of Rotterdam is also thanked for assistance and support during the startup phase of the survey. The authors also thank RWS Directorate Zuid-Holland, in particular Ad Schipperen and Arie Barendrecht, for providing vessels to conduct the boat surveys. Marc Sas of IMDC, Ltd., is gratefully acknowledged for providing instruments and personnel. Royal Boskalis Westminster, Ltd., is also thanked for providing a captain for the M.S. Tender. We also thank the EU 6th Framework Programme Project ECOOP, "European Coastal Sea Operational Observing and Forecasting System" for providing support for the preparation of this paper. We are grateful to Prof. Hans Burchard and an anonymous reviewer for their helpful comments on the paper.

\section{APPENDIX}

\section{Instantaneous Salinity and SPM Transport}

Figure A1 presents salt and SPM flux decomposition of advective transport at stations 1 and 2 . The advection of the ETM and the limited availability of SPM for transport can be deduced from comparisons of $\mathrm{T} 3$ and T4 SPM fluxes between stations 1 (Fig. A1c) and 2 (Fig. A1d) and from comparisons between SPM and salt fluxes at station 2 (Figs. A1b,d). Contrary to station 1, a peak is observed in the T4 SPM flux during flood (1300-1500) at station 2. This peak is associated with advection of the ETM, it lags the peak in T3 (Fig. A1d) associated with advection of background SPM. A comparison with the T4 salt flux at station 2 (Fig. A1b) between 1400 and 1530 associated with the tidal advection of the salt wedge supports this. However, after 1445 the T4 SPM flux decreases while the T4 salinity flux remains high. This difference in time evolution indicates the limited amount of SPM available for transport in comparison to salinity. This transport condition can also be inferred from a comparison of T3 and T4 SPM fluxes and T4 salinity and SPM fluxes at station 1 (Figs. A1a,c) between 1200 and 1600. The peak in negative T4 SPM flux occurs before the peak in negative T3 SPM flux, and the T4 SPM and salt fluxes are out of phase while the T3 salt and SPM fluxes are in phase. Hence, peak SPM concentrations occur before peak velocities and SPM concentrations drop before peak velocities because of the limited availability of SPM down-estuary of station 1 relative to salinity.

At station 1 (Fig. A1a) the salt balance is governed by the gravitational circulation and nonclosing tidal 
A
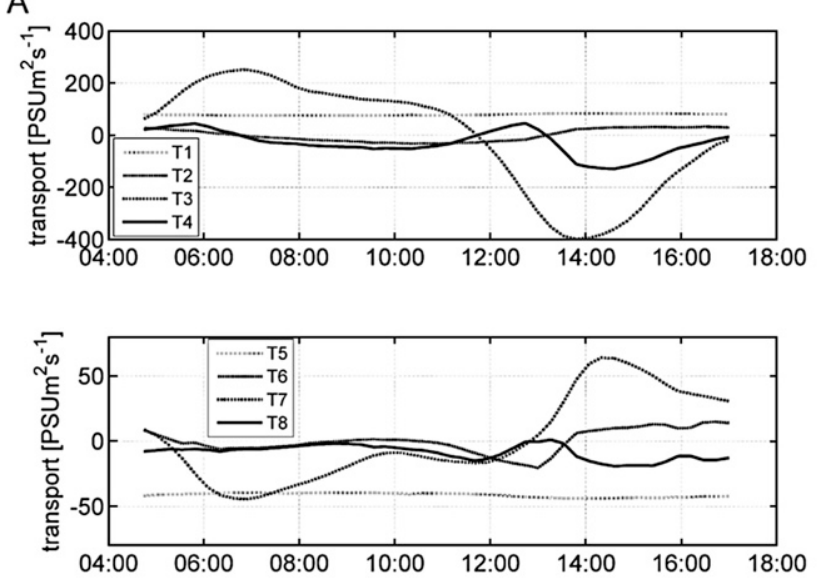

C
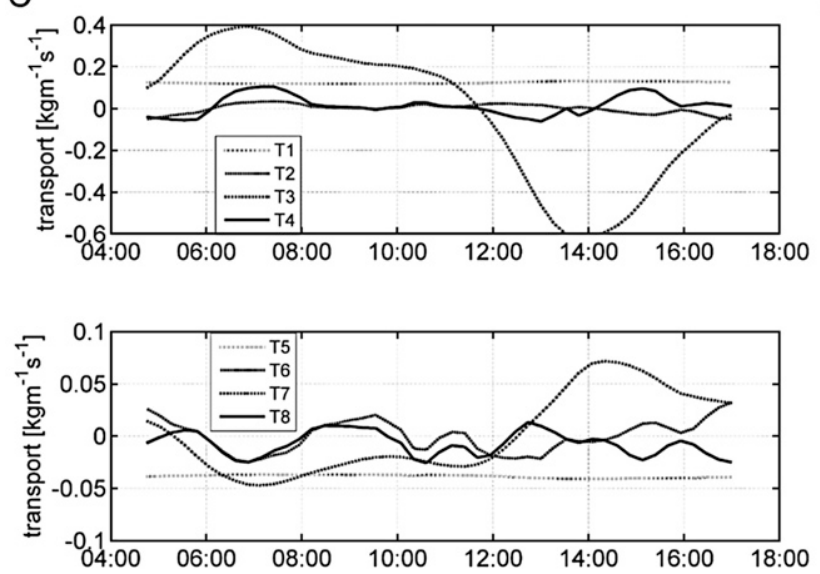

$B$
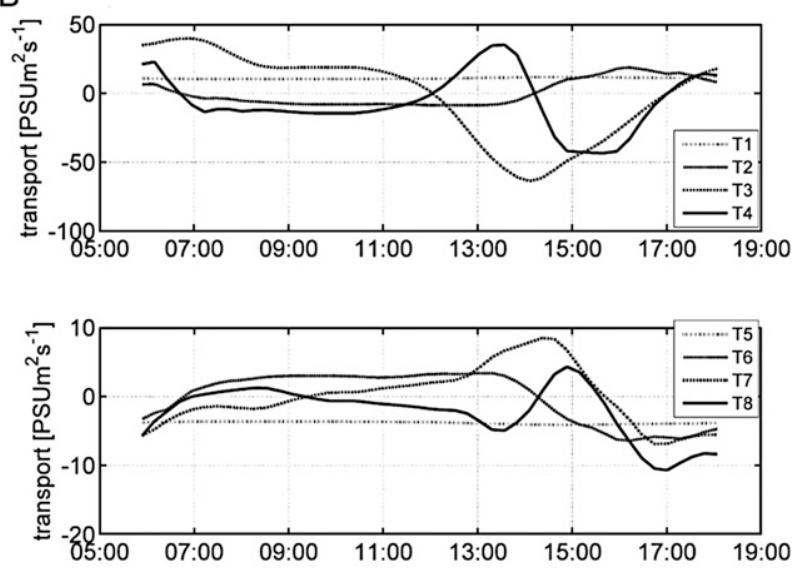

D
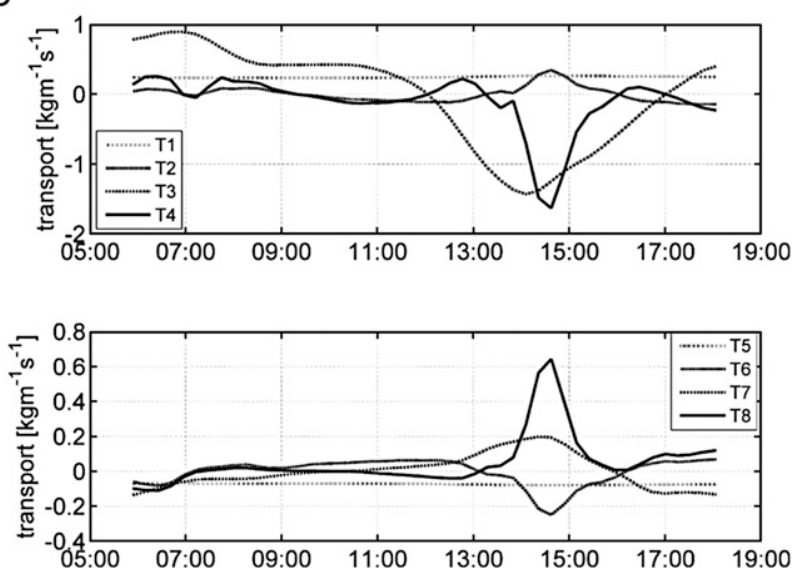

FIG. A1. The computed terms in the decomposition of the mass transports for the cross-sectional-averaged (top) salinity and (bottom) SPM transport per unit width [Eq. (2) terms T1-T8] at stations (a),(c) 1 and (b),(d) 2 during the survey on 11 Apr 2006. Positive values indicate seaward transport.

correlations associated with an asymmetry in advection of the salt wedge due to the diurnal inequality. However, at station 2 (Fig. A1b) T7 and T8 fluxes associated with baroclinic shear flows, particularly exchange flows around HWS (between 1600 and 1800), show a significant contribution to the up-estuary salt flux as well. A comparison of T5-T8 salt and SPM fluxes (Figs. A1b,d) shows similar time evolution from ebb to the beginning of flood. Differences in their (T6-T8 fluxes) time evolution during flood are likely due to differences in the along-channel distribution of salt and SPM. In contrast to the salt balance, the contribution of exchange flows to up-estuary transport of SPM (T7 and T8) around HWS (between 1600 and 1800) is limited to the T7 flux. This indicates the limited availability of SPM at the borders of the ETM.

\section{REFERENCES}

Allen, G. P., J. C. Salomon, P. Bassoullet, Y. Du Penhoat, and C. De Grandpré, 1980: Effects of tides on mixing and suspended sediment transport in macrotidal estuaries. Sediment. Geol., 26, 69-90.

Avoine, J., G. P. Allen, M. Nichols, J. C. Salomon, and C. Larsonneur, 1981: Suspended-sediment transport in the Seine estuary, France: Effect of man-made modifications on estuary-shelf sedimentology. Mar. Geol., 40, 119-137.

Brennon, I., and P. Le Hir, 1998: Modelling fine sediment dynamics in the Seine estuary: Interaction between turbidity patterns and sediment balance. Physics of Estuaries and Coastal Seas, J. Dronkers and M. Scheffers, Eds., Balkema, 431 pp.

— and — 1999: Modelling the turbidity maximum of the Seine Estuary (France): Identification of formation processes. Estuarine Coastal Shelf Sci., 49, 525-544.

Burchard, H., and H. Baumert, 1998: The formation of estuarine turbidity maxima due to density effects in the salt wedge. A hydrodynamic process study. J. Phys. Oceanogr., 28, 309-320.

Chant, R. J., and A. W. Stoner, 2001: Particle trapping in a stratified flood-dominated estuary. J. Mar. Res., 59, 29-51.

De Nijs, M. A. J., 2011: On sedimentation processes in a stratified estuarine system. Ph.D. thesis, Delft University of Technology, in press.

— J. C. Winterwerp, and J. D. Pietrzak, 2008: SPM variations in a harbour basin. Sediment and Ecohydraulics, Vol. 9, Proceedings in Marine Science, Elsevier, 357-378. 
,-- , and,- 2009 : On harbour siltation in the fresh-salt water mixing region. Cont. Shelf Res., 29, 175-193.

— J. D. Pietrzak, and J. C. Winterwerp, 2010: Advection of the salt wedge and evolution of the internal flow structure in the Rotterdam Waterway. J. Phys. Oceanogr., in press.

Downing, J., 2006: Twenty-five years with OBS sensors: The good, the bad, and the ugly. Cont. Shelf Res., 26, 2299-2318.

Dronkers, J., 1986: Tidal asymmetry and estuarine morphology. Neth. J. Sea Res., 20, 117-131.

Dyer, K., 1974: The salt balance in stratified estuaries. Estuarine Coastal Mar. Sci., 2, 273-281.

__ 1997: Estuaries: A Physical Introduction. 2nd ed. John Wiley and Sons, $195 \mathrm{pp}$.

Dyer, K. R., A. J. Bale, M. C. Christie, N. Feates, S. Jones, and A. J. Manning, 2002: The turbidity maximum in a mesotidal estuary, the Tamar estuary, UK: I. Dynamics of suspended sediment. Fine Sediment Dynamics in the Marine Environment, J. C. Winterwerp and C. Kranenburg, Eds., Elsevier Science, 203-218.

Eisma, D., J. Kalf, and M. Veenhuis, 1980: The formation of small particles and aggregates in the Rhine estuary. Neth. J. Sea Res., 14, 172-178.

_ G. C. Cadee, R. Laane, and J. Kalf, 1982: Preliminary results of Annelia and Navicula cruises in the Rhine and Ems estuaries, January - February, 1982 Mitt. Geol. Paläont. Inst. Univ. Hamburg SCOPE/UNEP Sonderb. 52, 633-654.

__ , and Coauthors, 1991: Suspended-matter particle size in some west-European estuaries; part I: Particle-size distribution. Neth. J. Sea Res., 28, 193-214.

Emery, W. J., and R. E. Thomson, 2001: Data Analysis Methods in Physical Oceanography. Elsevier, 638 pp.

Festa, J. F., and D. V. Hansen, 1978: Turbidity maxima in partially mixed estuaries: A two-dimensional numerical model. Estuarine Coastal Mar. Sci., 7, 347-359.

Fischer, H. B., 1972: Mass transport mechanisms in partially stratified estuaries. J. Fluid Mech., 53, 672-687.

—, E. J. List, R. C. Y. Koh, J. Imberger, and N. H. Brooks, 1979: Mixing in estuaries. Mixing in Inland and Coastal Waters, Academic Press, 229-278.

Gelfenbaum, G., 1983: Suspended-sediment response to semidiurnal and fortnightly tidal variations in a mesotidal estuary: Columbia River, U.S.A. Mar. Geol., 52, 39-57.

Geyer, W. R., 1993: The importance of suppression of turbulence by stratification on the estuarine turbidity maximum. Estuaries, 16, 113-125.

_ sediment in a partially mixed estuary. Physics of Estuaries and Coastal Seas, J. Dronkers and M. Scheffers, Eds., Balkema, $431 \mathrm{pp}$.

- J. H. Trowbridge, and M. M. Bowen, 2000: The dynamics of a partially mixed estuary. J. Phys. Oceanogr., 30, 2035-2048.

_ J. Woodruff, and P. Traykovski, 2001: Sediment transport and trapping in the Hudson River Estuary. Estuaries, 24, 670-679.

Grabemann, I., J. Kappenberg, and G. Krause, 1995: Aperiodic variations of the turbidity maxima of two German coastal plain estuaries. Neth. J. Aquat. Ecol., 29, 217-227.

— _ _ and _ 1996: Comparison of the dynamics of the turbidity maxima in two coastal plain estuaries. Adv. Limnol., 47, 195-205.

_ - R. J. Uncles, G. Krause, and J. A. Stephens, 1997: Behaviour of turbidity maxima in the Tamar (U.K.) and Weser (F.R.G.) estuaries. Estuarine Coastal Shelf Sci., 45, 235-246.

Groen, P., 1967: On the residual transport of suspended matter by an alternating tidal current. Neth. J. Sea Res., 3, 564-574.
Jay, D. A., 1991: Internal asymmetry and anharmonicity in estuarine flows. Progress in Tidal Hydrodynamics, B. B. Parker, Ed., John Wiley and Sons, 521-543.

— , and J. D. Musiak, 1994: Particle trapping in estuarine tidal flows. J. Geophys. Res., 99C, 445-461.

— and consequences. Mixing Processes in Estuaries and Coastal Seas, Coastal and Estuarine Studies Monogr., Vol. 50, Amer. Geophys. Union, 219-258.

Kappenberg, J., and I. Grabemann, 2001: Variability of the mixing zones and estuarine turbidity maxima in the Elbe and Weser estuaries. Estuaries, 24, 699-706.

Kirby, R., 1992: Detection and transport of high concentration suspensions. Proc. First Int. Conf. on the Pearl River Estuary in the Surrounding Area of Maccao, Macao, China, ICPRESAM, 69-84.

— , and W. R. Parker, 1977: The physical characteristics and environmental significance of fine-sediment suspensions in estuaries. Estuaries, Geophysics and the Environment, National Research Council, 110-120.

Kistner, D. A., and N. R. Pettigrew, 2001: A variable turbidity maximum in the Kennebec estuary, Maine. Estuaries, 24, 680 687.

Le Hir, P., and Coauthors, 2001: Fine sediment transport and accumulations at the mouth of the Seine Estuary (France). Estuaries, 24, 950-963.

Lin, J., and A. Y. Kuo, 2001: Secondary turbidity maximum in a micro-tidal partially-mixed estuary. Estuaries, 24, 707-720.

North, E. W., and E. D. Houde, 2003: Linking ETM physics, zooplankton prey and fish early life histories to stripped bass Morone saxatilis and white perch M. Americana recruitment. Mar. Ecol. Prog. Ser., 260, 219-236.

Orton, P. M., and G. C. Kineke, 2001: Comparing calculated and observed vertical suspended sediment distributions from a Hudson River Estuary turbidity maximum. Estuarine Coastal Shelf Sci., 52, 401-410.

Patchineelam, S. M., and B. Kjerfve, 2004: Suspended sediment variability on seasonal and tidal time scales in the Winyah Bay estuary, South Carolina, USA. Estuarine Coastal Shelf Sci., 59, 307-318.

Postma, H., 1961: Transport and accumulation of suspended matter in the Dutch Wadden Sea. Neth. J. Sea Res., 1, 148-190. , 1967: Sediment transport and sedimentation in the estuarine environment. Estuaries, G. H. Lauff, Ed., American Association for the Advancement of Science, 158-179.

Santema, P., 1953: Coagulatie van rivierslib bij ontmoeting met zeewater (Coagulation of river silt when meeting seawater). De Ingenieur, 16, B70-B72.

Schrottke, K., M. Becker, A. Bartholoma, and B. W. Flemming, 2006: Fluid mud dynamics in the Weser estuary turbidity zone tracked by high-resolution side-scan sonar and parametric sub-bottom profiler. Geo. Mar. Lett., 26, 185-198.

Schubel, J. R., 1968: Turbidity maximum of the northern Chesapeake Bay. Science, 161, 1013-1015.

Scully, M. E., and C. T. Friedrichs, 2003: The influence of asymmetries in overlying stratification on near-bed turbulence and sediment suspension in a partially mixed estuary. Ocean Dyn., 53 (3), 208-209.

Speer, P. E., and D. G. Aubrey, 1985: A study of non-linear tidal propagation in shallow inlet/estuarine systems. Part II: Theory. Estuarine Coastal Shelf Sci., 21, 207-224.

Uncles, R. J., and J. A. Stephens, 1989: Distributions of suspended sediment at high water in a macrotidal estuary. J. Geophys. Res., 94 (C10), 14 395-14 405. 
, and — 1993a: The freshwater-saltwater interface and its relationship to the turbidity maximum in the Tamar estuary, U.K. Estuaries, 16, 126-141.

— , and — 1993b: Nature of the turbidity maximum in the Tamar estuary U.K. Estuarine Coastal Shelf Sci., 36, 413-431.

— R. C. A. Elliot, and S. A. Weston, 1985: Observed fluxes of water, salt and suspended sediment in a partly mixed estuary. Estuarine Coastal Shelf Sci., 20, 147-167.

— - M. L. Barton, and J. A. Stephens, 1994: Seasonal variability of fine-sediment concentrations in the turbidity maximum region of the Tamar Estuary. Estuarine Coastal Shelf Sci., 38, 19-39.

— J. A. Stephens, and D. J. Law, 2006: Turbidity maximum in the macrotidal, highly turbid Humber Estuary UK: Flocs, fluid mud, stationary suspensions and tidal bores. Estuarine Coastal Shelf Sci., 67, 30-52.

van Leussen, W., 1994: Estuarine macroflocs and their role in finegrained sediment transport. Ph.D. thesis, Utrecht University, 484 pp.

-, and E. van Velzen, 1989: High concentration suspensions: Their origin and importance in Dutch estuaries and coastal waters. J. Coast. Res., 5 (Special Issue), 1-22.

van Veen, J., 1938: Water movements in the Straits of Dover. J. Cons. Int. Expl. Mer, 13, 7-36.

van Woudenberg, C., 1998: First results of preliminary measurements of suspended sediment in the Caland/Beerkanaal (in
Dutch). Public Works, Directorate North Sea, Rep. N98.02, $26 \mathrm{pp}$.

Verlaan, P. A. J., and R. Spanhoff, 2000: Massive sedimentation events at the mouth of the Rotterdam Waterway. J. Coastal Res., 16, 458-469.

Vlemmix, W., 1980: Metingen van de vertikale verdeling van het zwevende stofgehalte in het zeegebied voor de monding van de Waterweg, najaar 1978. (Measurements of the vertical distribution of suspended particulate matter in the area seaward of the mouth of the Rotterdam Waterway, in the fall of 1978). Public Works, Directorate North Sea, Rep. NZ-N80.04, 15 pp.

Wellershaus, S., 1981: Turbidity maximum and mud shoaling. Arch. Hydrobiol., 92, 161-198.

Weir, D. J., and J. McManus, 1987: The role of wind in generating turbidity maxima in the Tay Estuary. Cont. Shelf Res., 7,13151318.

Winterwerp, J. C., 1983: Decomposition of the mass transport in narrow estuaries. Estuarine Coastal Shelf Sci., 16, 627-638.

Wolanski, E., B. King, and D. Galloway, 1995: Dynamics of the turbidity maximum in the Fly River estuary, Papua New Guinea. Estuarine Coastal Shelf Sci., 40, 321-337.

_ N. N. Huan, L. T. Dao, N. H. Nhan, and N. N. Thuy, 1996: Fine-sediment dynamics in the Mekong River estuary, Vietnam. Estuarine Coastal Shelf Sci., 43, 565-582. 